\title{
Changes in fatty acids in plasma and association with the inflammatory response in dairy cows abomasally infused with essential fatty acids and conjugated linoleic acid during late and early lactation
}

\author{
M. Gnott, ${ }^{1}$ L. Vogel, ${ }^{1}$ C. Kröger-Koch, ${ }^{1}$ D. Dannenberger, ${ }^{2}$ A. Tuchscherer, ${ }^{3}$ A. Tröscher, ${ }^{4} \odot$ E. Trevisi, ${ }^{5}$ () \\ T. Stefaniak, ${ }^{6} \odot$ J. Bajzert, ${ }^{6}{ }^{6}$ A. Starke, ${ }^{7}$ M. Mielenz, ${ }^{1} \odot$ L. Bachmann, ${ }^{1} \oplus$ and H. M. Hammon ${ }^{1 *} \odot$ \\ ${ }^{1}$ Institute of Nutritional Physiology "Oskar Kellner," Leibniz Institute for Farm Animal Biology (FBN), 18196 Dummerstorf, Germany \\ ${ }^{2}$ Institute of Muscle Biology and Growth, Leibniz Institute for Farm Animal Biology (FBN), 18196 Dummerstorf, Germany \\ ${ }^{3}$ Institute of Genetics and Biometry, Leibniz Institute for Farm Animal Biology (FBN), 18196 Dummerstorf, Germany \\ ${ }^{4}$ BASF SE, 68619 Lampertheim, Germany \\ ${ }^{5}$ Department of Animal Sciences, Food and Nutrition (DIANA), Università Cattolica del Sacro Cuore, 29122 Piacenza, Italy \\ ${ }^{6}$ Department of Immunology, Pathophysiology and Veterinary Preventive Medicine, Faculty of Veterinary Medicine, \\ Wroclaw University of Environmental and Life Science, 50-375 Wroclaw, Poland \\ ${ }^{7}$ Clinic for Ruminants and Swine, Faculty of Veterinary Medicine, University of Leipzig, 04103 Leipzig, Germany
}

\begin{abstract}
Dairy cows are exposed to increased inflammatory processes in the transition period from late pregnancy to early lactation. Essential fatty acids (EFA) and conjugated linoleic acid (CLA) are thought to modulate the inflammatory response in dairy cows. The present study investigated the effects of a combined EFA and CLA infusion on the fatty acid (FA) status in plasma lipids, and whether changes in the FA pattern were associated with the acute phase and inflammatory response during late pregnancy and early lactation. Rumen-cannulated Holstein cows $(\mathrm{n}=40)$ were assigned from wk 9 antepartum to wk 9 postpartum to 1 of 4 treatment groups. Cows were abomasally supplemented with coconut oil (CTRL, $76 \mathrm{~g} / \mathrm{d}$ ), linseed and safflower oil (EFA, $78 \mathrm{~g} / \mathrm{d}$ of linseed oil and $4 \mathrm{~g} / \mathrm{d}$ of safflower oil; ratio of oils $=$ 19.5:1; n-6:n-3 FA ratio = 1:3), Lutalin $($ CLA, $38 \mathrm{~g} / \mathrm{d}$; isomers cis-9,trans-11 and trans-10,cis-12; each $10 \mathrm{~g} / \mathrm{d}$ ), or both (EFA+CLA). Blood samples were taken to measure changes in FA in blood plasma on $\mathrm{d}-63,-42$, 1,28 , and 56, and in plasma lipid fractions (cholesterol esters, free fatty acids, phospholipids, and triglycerides) on $\mathrm{d}-42,1$, and 56 relative to calving, and in erythrocyte membrane (EM) on d 56 after calving. Traits related to the acute phase response and inflammation were measured in blood throughout the study. Liver samples were obtained for biopsy on $\mathrm{d}-63,-21,1$,
\end{abstract}

Received April 17, 2020.

Accepted July 15, 2020.

*Corresponding author: hammon@fbn-dummerstorf.de
28 , and 63 relative to calving to measure the mRNA abundance of genes related to the inflammatory response. The concentrations of $\alpha$-linolenic acid and n-3 FA metabolites increased in lipid fractions (especially phospholipids) and EM due to EFA supplementation with higher $\alpha$-linolenic acid but lower n-3 metabolite concentrations in EFA+CLA than in EFA treatment only. Concentration of linoleic acid decreased in plasma fat toward calving and increased during early lactation in all groups. Concentration of plasma arachidonic acid was lower in EFA- than in non-EFA-treated groups in lipid fractions and EM. The cis-9,trans-11 CLA increased in all lipid fractions and EM after both CLA treatments. Plasma haptoglobin was lowered by EFA treatment before calving. Plasma bilirubin was lower in EFA and CLA than in CTRL at calving. Plasma concentration of IL-1 $\beta$ was higher in EFA than in CTRL and EFA+CLA at certain time points before and after calving. Plasma fibrinogen dropped faster in CLA than in EFA and EFA+CLA on d 14 postpartum. Plasma paraoxonase tended to be elevated by EFA treatment, and was higher in EFA+CLA than in CTRL on d 49. Hepatic mRNA abundance revealed time changes but no treatment effects with respect to the inflammatory response. Our data confirmed the enrichment of n-3 FA in EM by EFA treatment and the inhibition of n-3 FA desaturation by CLA treatment. The elevated n-3 FA status and reduced n-6:n-3 ratio by EFA treatment indicated a more distinct effect on the inflammatory response during the transition period than the single CLA treatment, and the combined EFA+CLA treatment caused minor additional changes on the antiinflammatory response.

Key words: $\alpha$-linolenic acid, conjugated linoleic acid, lipid fraction, inflammatory response 


\section{INTRODUCTION}

Essential fatty acids (EFA) have been shown to have beneficial effects in a wide variety of diseases in humans and animals, including dairy cows (Zamaria, 2004; Palmquist, 2010; Moallem, 2018). The immunomodulatory effects of EFA are mostly mediated through eicosanoid synthesis (e.g., prostaglandins, leukotrienes, and thromboxanes) from EFA. The main n-3 fatty acids (FA) are $\alpha$-linolenic acid (ALA) with the metabolites eicosapentaenoic acid (EPA), docosapentaenoic acid (DPA), and docosahexaenoic acid (DHA); the main n-6 FA are linoleic acid (LA) and arachidonic acid (ARA; James et al., 2000). Generally, EFA of the n-3 series are known to be less inflammatory than n-6 EFA (James et al., 2000; Sordillo, 2016; Moallem, 2018). The changes in the n-6:n-3 FA ratio directly affect the production of mediators that are involved in the secretion of proinflammatory cytokines, such as TNF (tumor necrosis factor- $\alpha$ ), IL-1 $\beta$, and IL-6 (Simopoulos, 2016), and may also affect acute phase response in dairy cows around calving (Silvestre et al., 2011). The acute phase proteins (APP) play major roles in several aspects of the systemic reaction to inflammation and exert multiple systemic functions, including the adaptation of the energy and protein metabolism and the protection of tissue for excessive inflammatory alterations (Fleck, 1989; Ceciliani et al., 2012). Any effort to reduce the acute phase response in the transition period would be useful for optimizing the productive performance of high-yielding dairy cows (Bertoni et al., 2008; Trevisi et al., 2015). The APP response is triggered to a large extent by the production of interleukins, especially IL$1 \beta$ and IL-6 (Fleck, 1989; Bertoni and Trevisi, 2013; Trevisi et al., 2015).

The plasma lipid fractions consist of cholesterol esters (CE), free fatty acids (FFA), phospholipids (PL), and triglycerides (TG). In addition to PL in cell membranes, PL and CE in plasma are a large reservoir for EFA that supply organs and tissues and influence their functions. Incorporation of FA varies between distinct blood lipid pools, and follows fluctuationinduced changes from late pregnancy to early lactation (Christie, 1981; Malovrh et al., 2014). Essential fatty acids such as ALA and LA cannot be synthesized by mammals, including ruminants, and must be delivered by food (Palmquist, 2010). In addition, CLA isomers are produced in the rumen by EFA transformation. Therefore, rumen CLA production depends on EFA intake (Chilliard et al., 2001; Shingfield et al., 2010). The isomer-specific, health-promoting effects of CLA in humans are well known (Nagao and Yanagita, 2005; Shokryazdan et al., 2017). Some of the CLA isomers reveal metabolic effects in dairy cows (e.g., milk fat reduction and glucose-sparing effects; Bauman et al., 2000; Hötger et al., 2013). These effects are able to improve the glucose status of dairy cows, which may have consequences for milk production and the immune response during the transition period (Baumgard et al., 2017). Therefore, especially in the transition period, the metabolic and immune function of dairy cows via EFA (especially n-3 FA) or CLA supply is of high interest.

The aim of the present study was to investigate the FA composition in plasma lipid fractions and erythrocyte membranes (EM) during supplementation with EFA and CLA alone and in combination. In addition, the effect of such a combined EFA and CLA treatment on the acute phase and inflammatory response of dairy cows during late pregnancy and early lactation was studied. A combined EFA and CLA supplementation refers to the supply of EFA and related rumen and tissue CLA production in dairy cows receiving fresh grass or on pasture (Kelly et al., 1998; Ferlay et al., 2006; Lahlou et al., 2014). Doses for the supplied EFA (linseed and safflower oil in a ratio of 19.5:1, providing an n-6:n-3 FA ratio of 1:3 in the supplement mixture) and CLA were recently evaluated in a companion doseresponse study in mid-lactating dairy cows (Haubold et al., 2020). To avoid rumen degradation of the supplemented FA, all FA were infused into the abomasum (Vogel et al., 2020). We hypothesized that an elevated combined EFA and CLA intake would change the plasma FA pattern and affect the inflammatory response of dairy cows during the transition from late pregnancy to early lactation.

\section{MATERIALS AND METHODS}

\section{Animals, Housing, Feeding, and FA Supplementation}

The experimental procedures were carried out according to animal welfare guidelines and were approved by the relevant authorities of the state Mecklenburg-Western Pomerania, Germany (LALLF M-V/ TSD/7221.3-1-038/15). For the present study, 40 German Holstein cows in the first third of their second lactation (expected milk yield of $11,000 \mathrm{~kg} / 305 \mathrm{~d}$ ) were purchased from a local farm (Agrarprodukte Dedelow $\mathrm{GmbH}$, Prenzlau, Germany), kept in the experimental animal facility for cattle of the Leibniz Institute for Farm Biology (FBN, Dummerstorf, Germany), and adapted to the feeding and housing conditions. Cows were surgically equipped with a rumen cannula $(10-\mathrm{cm}$ center diameter cannula; Bar Diamond Inc., Parma, ID) $8 \mathrm{wk}$ before the start of the experiments; access to the abomasum via the rumen for FA infusion has 
recently been described (Haubold et al., 2020; Vogel et al., 2020). The presented investigations were part of a comprehensive project regarding the effects of EFA and CLA supplementation on performance and metabolism in transition dairy cows (Vogel et al., 2020). The cows were investigated from wk 9 antepartum (ap) until wk 9 postpartum (pp); animal management, performance data, and milk and carcass composition have been described recently (Vogel et al., 2020).

Feeding and housing management was the same for all cows during the experimental period. Briefly, animals were kept in a loose-housing freestall barn and were fed ad libitum with a corn silage-based TMR that was adapted for the dry period (wk 6 to 0 ap) as well as late- (wk 10 to $7 \mathrm{ap}$ ) and early-lactation periods (wk 1 to $8 \mathrm{pp}$ ). The TMR provided low amounts of fat and low n-3 FA supply, but contained a significant concentration of LA. Therefore, we obtained a high $n$ -6:n-3 ratio in the FA profile of plasma and milk fat in cows fed with this diet (Weber et al., 2016; Revskij et al., 2019; Vogel et al., 2020). The chemical composition of the 2 different diets was determined according to the recommendations of the German Society of $\mathrm{Nu}$ tritional Physiology (GfE, 2001, 2008; Table 1). The FA composition of the diets is shown in Table 2. The final n-6:n-3 FA ratio in the diets was increased to 7:1. Feed samples from TMR and corn silage were taken weekly and analyzed according to the Weender standard procedure (Naumann and Bassler, 2012) at the Agricultural Analysis and Research Institute (LUFA, Rostock, Germany). Cows had free access to water and were milked twice a day at 0630 and $1800 \mathrm{~h}$ during late and early lactation.

The cows were examined in 5 blocks of 8 animals each. The blocks started 1 after the other every 3 mo such that the whole study lasted $\sim 21$ mo in total. For each block, 8 cows were purchased such that expected calving date of each block was within 3 wk. In addition, milk yield of all cows had to be within 10,000 to $12,500 \mathrm{~kg} / 305 \mathrm{~d}$ during second lactation (mean \pm SD: $11,101 \pm 1,118 \mathrm{~kg}$ of milk $/ 305 \mathrm{~d}$ ). Cows within a block did not differ in BW (mean \pm SD: $662 \pm 56$ $\mathrm{kg}$ ) and predicted calving interval (mean \pm SD: $395 \pm$ $39 \mathrm{~d}$ ). Two cows per block were randomly assigned to 1 of 4 treatment groups (Vogel et al., 2020): control group (CTRL; coconut oil, Sanct Bernhard, Bad Ditzenbach, Germany; $\mathrm{n}=9$ ); EFA (linseed oil; DERBY, Derby Spezialfutter GmbH, Münster, Germany and safflower oil; GEFRO, GC Memmingen/Allgäu, Germany; ratio of $19.5: 1$, providing an $\mathrm{n}-6 \mathrm{n} \mathrm{n}-3 \mathrm{FA}$ ratio of $1: 3$ in the supplement mixture; $\mathrm{n}=9$ ); CLA (Lutalin: cis-9,trans-11 and cis-10,trans-12 CLA; BASF, Ludwigshafen, Germany; $\mathrm{n}=10$ ); and the combination of EFA
Table 1. Ingredients and chemical composition of the diets

\begin{tabular}{|c|c|c|}
\hline \multirow[b]{2}{*}{ Item, $\mathrm{g} / \mathrm{kg}$ of DM } & \multicolumn{2}{|c|}{ Diet } \\
\hline & Lactation & Dry period $^{1}$ \\
\hline \multicolumn{3}{|l|}{ Ingredient } \\
\hline Corn silage & 457 & 421 \\
\hline Straw & 97 & 223 \\
\hline Concentrates $^{2}$ (granulated) & 446 & - \\
\hline Dried sugar beet pulp & - & 163 \\
\hline Extracted soybean meal & - & 99 \\
\hline Rye grain & - & 75 \\
\hline Minerals $^{3}$ & - & 10 \\
\hline Urea $^{4}$ & - & 9 \\
\hline \multicolumn{3}{|l|}{ Chemical composition } \\
\hline $\mathrm{NE}_{\mathrm{L}},{ }^{5} \mathrm{MJ} / \mathrm{kg}$ of $\mathrm{DM}$ & 7.1 & 6.5 \\
\hline Crude fat & 23 & 21 \\
\hline Crude fiber & 173 & 219 \\
\hline $\mathrm{CP}$ & 146 & 141 \\
\hline Utilizable protein $^{5}$ & 143 & 141 \\
\hline NFC & 432 & 379 \\
\hline $\mathrm{NDF}$ & 346 & 423 \\
\hline $\mathrm{ADF}$ & 197 & 249 \\
\hline $\mathrm{RNB}^{5,6}$ & 0.5 & 0.0 \\
\hline
\end{tabular}

${ }^{1}$ The dry period diet was fed from wk 6 to 1 before calving.

${ }^{2}$ Ceravis AG, Malchin, Germany. Ingredients: $46.5 \%$ dried sugar beet pulp, $25.3 \%$ extracted soybean meal, $23.8 \%$ rye grain, $1.4 \%$ urea, $1.1 \%$ premix cow, $1.00 \%$ calcium, $0.37 \%$ phosphorus, $0.42 \%$ sodium, vitamins $\mathrm{A}, \mathrm{D}_{3}, \mathrm{E}$, copper, ferric, zinc, manganese, cobalt, iodine, and selenium. Chemical composition: $44.4 \%$ NFC, $24.1 \% \mathrm{CP}, 21.6 \% \mathrm{NDF}$, $12.4 \%$ ADF, $9.3 \%$ crude fiber, $8.2 \%$ crude ash, $1.8 \%$ crude fat, $7.9 \mathrm{MJ}$ of $\mathrm{NE}_{\mathrm{L}} / \mathrm{kg}$ of DM.

${ }^{3}$ KULMIN MFV Plus (Bergophor Futtermittelfabrik Dr. Berger GmbH and Co. KG, Kulmbach, Germany): 8.5\% magnesium, $7.5 \%$ phosphorus, $6.5 \%$ sodium, $3.5 \% \mathrm{HCl}$-insoluble ash, $1.5 \%$ calcium, additives: vitamins $\mathrm{A}, \mathrm{D}_{3}, \mathrm{E}, \mathrm{B}_{1}, \mathrm{~B}_{2}, \mathrm{~B}_{6}, \mathrm{~B}_{5}, \mathrm{~B}_{3}, \mathrm{~B}_{12}, \mathrm{~B}_{9}, \mathrm{H}$, zinc, manganese, copper, cobalt, iodine, selenium, and Saccharomyces cerevisiae.

${ }^{4}$ Piarumin (SKW Stickstoffwerke Piesteritz GmbH, Lutherstadt Wittenberg, Germany); 99\% urea, $46.5 \%$ total nitrogen.

${ }^{5}$ German Society of Nutrition Physiology (GfE 2001, 2008, 2009) and Deutsche Landwirtschaftliche Gesellschaft (DLG, 2013).

${ }^{6} \mathrm{RNB}=$ ruminal nitrogen balance.

and CLA (EFA+CLA; $\mathrm{n}=10)$. Two cows calved prematurely and had to be excluded from the study. Data from these 2 cows were not included in the statistical analyses. Cows were abomasally supplemented from $\mathrm{d}$ -63 ap until d $63 \mathrm{pp}$. The dosages of the daily abomasally infused supplements are shown in Table 3, and the FA composition of the infused lipids is presented in Supplemental Table S1 (https://doi.org/10.3168/jds .2020-18735). Dosages of FA applications were chosen based on a previous study (Haubold et al., 2020). Cows were supplemented with 2 equal portions of daily doses in the morning $(0700 \mathrm{~h})$ and afternoon $(1630 \mathrm{~h})$. The daily dose of infused fats was halved during the dry period. The drying period started at 6 wk before expected calving, and cows received dry period antibiotics (Benestermycin, Vetmedica GmbH, Ingelheim, Germany) and a teat concealer (Calgodip Zitzenversiegler T- Hexx dry, Calvatis GmbH, Germany). 
Table 2. Fatty acid composition of the experimental diets

\begin{tabular}{|c|c|c|}
\hline \multirow[b]{2}{*}{ Fatty acid, $\mathrm{g} / \mathrm{kg}$ of $\mathrm{DM}$} & \multicolumn{2}{|c|}{ Diet } \\
\hline & Lactation & Dry period ${ }^{1}$ \\
\hline 10:0 & 0.01 & 0.01 \\
\hline $12: 0$ & 0.04 & 0.03 \\
\hline 14:0 & 0.12 & 0.18 \\
\hline $15: 0$ & 0.04 & 0.04 \\
\hline 16:0 & 4.73 & 4.53 \\
\hline $16: 1$ cis-9 & 0.06 & 0.05 \\
\hline $17: 0$ & 0.09 & 0.08 \\
\hline $17: 1$ cis-9 & 0.01 & 0.01 \\
\hline $18: 0$ & 0.63 & 0.60 \\
\hline $18: 1$ cis-9 & 4.82 & 3.84 \\
\hline 18:1 cis-11 & 0.28 & 0.21 \\
\hline $18: 2$ cis- 9 , cis- 12 & 9.63 & 9.32 \\
\hline $18: 3$ cis -9, cis- 12, cis -15 & 1.35 & 1.37 \\
\hline 18:4 cis-6,cis-9,cis-12,cis-15 & 0.04 & 0.02 \\
\hline 20:0 & 0.15 & 0.16 \\
\hline $20: 1$ cis-11 & 0.08 & 0.06 \\
\hline $20: 2$ cis- 11, cis- 14 & 0.05 & 0.02 \\
\hline $21: 0$ & 0.01 & 0.02 \\
\hline $22: 0$ & 0.18 & 0.25 \\
\hline $22: 1$ cis -13 & 0.01 & - \\
\hline $22: 2$ cis- 13, cis- 16 & 0.01 & 0.04 \\
\hline 23:0 & 0.05 & 0.02 \\
\hline 24:0 & 0.23 & 0.29 \\
\hline $\mathrm{SFA}^{2}$ & 6.27 & 6.21 \\
\hline MUFA $^{3}$ & 5.27 & 4.17 \\
\hline $\mathrm{PUFA}^{4}$ & 11.08 & 10.77 \\
\hline Sum of n-3 fatty acids ${ }^{5}$ & 1.39 & 1.39 \\
\hline Sum of $n-6$ fatty acids ${ }^{6}$ & 9.69 & 9.38 \\
\hline n-6:n-3 ratio & 7.00 & 6.76 \\
\hline
\end{tabular}

${ }^{1}$ The dry period diet was fed from wk 6 to 0 before calving.

${ }^{2}$ Sum of 10:0; 12:0; 14:0; 15:0; 16:0; 17:0; 18:0; 20:0; 21:0; 22:0; 23:0; and 24:0.

${ }^{3}$ Sum of $16: 1$ cis-9; 17:1 cis-9; 18:1 cis-9; 18:1 cis-11; 20:1 cis-11; and $22: 1$ cis- 13

${ }^{4}$ Sum of $18: 2$ cis-9,cis-12; 18:3 cis-9,cis- 12, cis- $15 ; 18: 4$ cis-6, cis-9,cis12,cis-15; $20: 2$ cis-11,cis-14; and 22:2 cis-13,cis-16.

${ }^{5}$ Sum of $18: 3$ cis-9,cis-12, cis-15 and 18:4 cis-6,cis-9,cis-12,cis-15.

${ }^{6}$ Sum of 18:2 cis-9,cis-12; 20:2, cis-11,cis-14; and 22:2 cis-13,cis-16.

\section{Blood Plasma Sampling, Preparation of EM, and Analyses}

Blood samples were taken at $63,42,35,28,21$, and $10 \mathrm{~d}$ before expected parturition, on d 1 after calving, and weekly thereafter up to d 56 pp from the jugular vein into evacuated tubes (Vacuette, Greiner Bio-One International AG, Kremsmünster, Austria). Blood was collected in the morning after milking and before subsequent feeding. Immediately after collection, samples were placed on ice and then centrifuged at 1,500 $\times g$ at $4^{\circ} \mathrm{C}$ for $20 \mathrm{~min}$. Extracted plasma was aliquoted and frozen at $-20^{\circ} \mathrm{C}$ until analysis of FA and metabolites, and at $-80^{\circ} \mathrm{C}$ until analysis of APP and interleukins. Additionally, at d $56 \mathrm{pp}$, EM were prepared according to a modified procedure of Kamata et al. (2008). After centrifugation $\left(2,200 \times g\right.$ at $4^{\circ} \mathrm{C}$ for $\left.15 \mathrm{~min}\right)$ and plasma collection, the buffy coat and the first layer of the erythrocytes were discarded. The remaining erythrocytes were washed 3 times with Tris-buffered saline and centrifuged at $2,200 \times g$ at $4^{\circ} \mathrm{C}$ for $10 \mathrm{~min}$. Thereafter, $10 \mu \mathrm{L}$ of butylhydroxytoluol $(2 \%)$ was added as an antioxidant to $2 \mathrm{~mL}$ of concentrated erythrocytes, and samples were stored at $-80^{\circ} \mathrm{C}$ until analyses of $\mathrm{EM}$ for FA.

Bilirubin from samples containing sodium fluoride and potassium oxalate $(2-4$ and $1-3 \mathrm{mg} / \mathrm{mL}$, respectively) was measured using an automatic spectrophotometer (ABX Pentra 400; Horiba ABX, Montpellier, France, \#LT-BR0500). Plasma haptoglobin was determined from blood samples with lithium-heparin (12-30 IU of heparin $/ 10 \mathrm{~mL}$ ) used as an anticoagulant and by the method described by Skinner et al. (1991). The haptoglobin measurement was adapted to the ILAB600 condition (Calamari et al., 2016), which is based on the peroxidase activity of the methemoglobin-haptoglobin complex measured by the rate of oxidation of guaiacol (hydrogen donor) in the presence of hydrogen peroxide (oxidizing substrate). Bovine interleukins IL-1 $\beta$ (cat. no. ESS0027; Thermo Scientific, Frederick, MD) and IL-6 (cat. no. ESS0029; Thermo Scientific) plasma concentrations were determined using commercial bovine-specific colorimetric sandwich ELISA kits according to Trevisi et al. (2015). The intra- and interassay coefficients of variation were $4.5 \%$ and $17.0 \%$, and $3.5 \%$ and $13.4 \%$ for IL- $1 \beta$ and IL- 6 , respectively. Plasma paraoxonase was measured by the method of Ferré et al. (2002) adapted to the ILAB 650 apparatus, as previously described by Trevisi et al. (2018). Plasma fibrinogen was determined by rapid heat precipitation according to Millar et al. (1971). Plasma concentrations of immunoglobulins $\operatorname{IgG}_{1}, \operatorname{IgG}_{2}$, and $\operatorname{IgM}$ were measured at d 63, 42, and 21 ap and on d 1, 14, 28, 42, and 56 pp via ELISA (no. E10-116, E10-117, E10-101, Bethyl Laboratories Inc., Montgomery, TX; Gerbert et al., 2018). The intra- and interassay coefficients of variation were $3.1 \%$ and $2.7 \%$ for $\operatorname{IgG}_{1}, 2.8 \%$ and $1.7 \%$ for $\operatorname{IgG}_{2}$, and $4.2 \%$ and $2.9 \%$ for IgM. For the statistical analyses of the data, time points of sampling at which cows presented clinical symptoms of disease were retrospectively excluded from the analysis.

\section{Plasma Lipid Extraction and FA Analyses}

The FA composition in plasma was measured in blood samples containing EDTA $\left(\mathrm{K}_{3} \mathrm{EDTA}, 1.8 \mathrm{~g} / \mathrm{L}\right)$ at $\mathrm{d}-63,-42,1,28$ and 56 relative to calving. Lipid extraction and separation of lipid fractions (i.e., CE, FFA, PL, and TG) from blood plasma were performed at $\mathrm{d}-42,1$, and 56 relative to calving and additionally in EM at d $56 \mathrm{pp}$. The detailed sample preparation procedure was previously described by Dannenberger 
Table 3. Amounts of daily abomasally infused supplements ${ }^{1}$

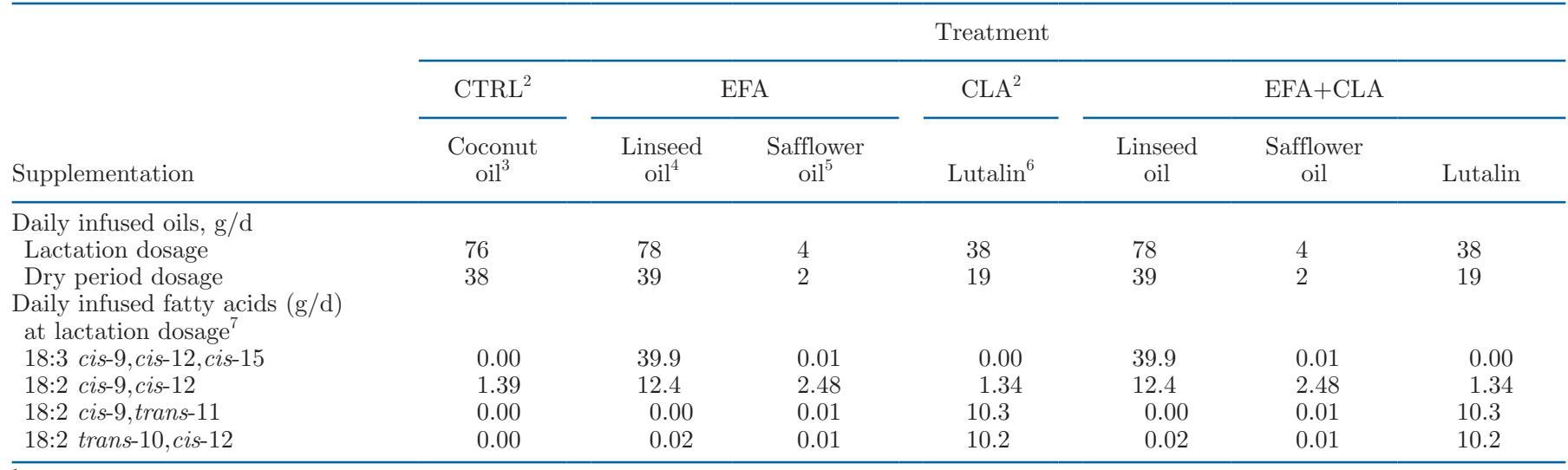

${ }^{1}$ Cows were supplemented daily with coconut oil (CTRL), linseed and safflower oil (EFA), Lutalin (CLA, cis-9,trans-11 and trans-10,cis-12), or both (EFA+CLA).

${ }^{2}$ Addition of vitamin E (0.06 g/d), Covitol 1360 (BASF, Ludwigshafen, Germany), to compensate for vitamin E in linseed oil (0.07\%) and safflower oil $(0.035 \%)$.

${ }^{3}$ Sanct Bernhard, Bad Ditzenbach, Germany.

${ }^{4}$ DERBY, Derby Spezialfutter GmbH, Münster, Germany.

${ }^{5}$ GEFRO, Memmingen/Allgäu, Germany.

${ }^{6}$ BASF, Ludwigshafen, Germany.

${ }^{7}$ The dosage for lactation was halved during the dry period.

et al. (2017). The FA analysis of the cow plasma lipids was performed using capillary gas chromatography with a CP-Sil $88 \mathrm{CB}$ column $(100 \mathrm{~m} \times 0.25 \mathrm{~mm}$, Agilent, Santa Clara, CA) that was installed in a PerkinElmer gas chromatograph CLARUS 680 with a flame ionization detector and split injection (PerkinElmer Instruments, Shelton) as described by Dannenberger et al. (2012). We used C19:0 as an internal standard for the quantification of FA. For the calibration procedure, we used the reference standard mixture Sigma FAME (Sigma-Aldrich, Deisenhofen, Germany), the methyl ester of C18:1cis-11, C22:5n-3, and C18:2cis-9,trans -11 (Matreya, PA), C22:4n-6 (Sigma-Aldrich, Deisenhofen, Germany), and C18:4n-3 (Larodan, Limhamn, Sweden). The 5-point calibration of a single FA ranged between 16 and $415 \mu \mathrm{g} / \mathrm{mL}$ and was checked after GC analysis of 5 samples.

\section{Liver Tissue Sampling and Analyses}

Liver biopsies were collected on d $-63,-21,1,28$ and 63 relative to calving. Skin was cut under local anesthesia, and liver tissue was extracted using a tailormade biopsy needle with an outer diameter of $6 \mathrm{~mm}$ (Weber et al., 2013). Extracted liver tissue was immediately frozen in liquid nitrogen and stored at $-80^{\circ} \mathrm{C}$ until analysis. After pulverization in liquid nitrogen, the RNA was extracted from homogenized liver tissue with TRIzol reagent (Life Technologies, Darmstadt, Germany) and cleaned with a RNeasy Mini Kit (Qia- gen $\mathrm{GmbH}$ ). The RNA quality was determined with an Agilent 2100 Bioanalyzer (Agilent Technologies). The mean RNA integrity number of all samples was $6 \pm 1$. The RNA integrity was checked by gel electrophoresis when the RNA integrity number was lower than 6 to make sure that RNA was not degraded. The quantity and purity of the total RNA were also measured by the optical density via a spectrophotometer (NanoPhotometer, Implen GmbH, Munich, Germany) at 260:280. Quantification of the relative mRNA abundance of selected genes was conducted as previously described (Saremi et al., 2012b). We used LRP10 and HPCAL1 as reference genes. Primer sequences, accession numbers, and PCR conditions for target genes are listed in Supplemental Table S2 (https://doi.org/10.3168/jds .2020-18735). The selected target genes related to inflammatory and immune responses were TNFA, IL1A, IL1B, HP, SAA2, FGA, CRP, TLR4, and PON1, and genes associated with prostaglandin synthesis were COX1 and COX2. Primer products were verified by sequencing using the BigDye Terminator v1.1 Cycle Sequencing kit and an ABI 3130 Genetic Analyzer (Life Technologies, Carlsbad, CA). Relative mRNA amounts of the investigated genes were determined by real-time PCR (LightCycler 96, Roche Molecular Biochemicals, Mannheim, Germany) and SYBR green I detection. Melting curve analysis and agarose gel electrophoresis were used for verification of PCR products. Quantification cycle values and amplification efficiencies received with the use of LinRegPCR version 2017.0 (Ruijter 
et al., 2013) were imported into qBASE+ version 3.1 (Biogazelle, Gent, Belgium) for all of the following calculations and quality controls. For normalization, the geometric mean of the reference gene abundance was used.

\section{Statistical Analyses}

Statistical analyses were conducted with SAS for Windows (version 9.4; SAS Institute Inc., Cary, NC). Plasma concentrations of immune and inflammatory traits, FA in plasma and plasma lipids, and hepatic mRNA abundance data were analyzed by repeatedmeasures ANOVA using the MIXED procedure, and a model containing EFA (levels: yes, no), CLA (levels: yes, no), time (levels: d relative to calving), block (levels: $1-5)$, and the respective interactions $(\mathrm{EFA} \times \mathrm{CLA}$, $\mathrm{EFA} \times$ time, $\mathrm{CLA} \times$ time, and $\mathrm{EFA} \times \mathrm{CLA} \times$ time) as fixed effects. The calving interval and milk yield in the second lactation were used as covariates. The most suitable covariance structure was the compound symmetry. For the analyses of plasma metabolites (haptoglobin, fibrinogen, paraoxonase, bilirubin, IL-6, and IL-1 $\beta$ ), the following distinct time periods were evaluated: antepartum (d 63, 42, 35, 28, 21, and $10 \mathrm{ap})$, transition (d 21,10 ap and $\mathrm{d} 1,7,14,21$, and $28 \mathrm{pp}$ ), postpartum (d 1, 7, 21, 28, 35, 42, 49, and $56 \mathrm{pp}$ ), and the entire period of the study (d 63 ap to d $56 \mathrm{pp}$ ). The analyses of plasma FA, plasma immunoglobulins, and mRNA abundance in the liver were only calculated for the entire period due to fewer sampling time points. The least squares means (LSM) and their standard errors were computed for each fixed effect in the ANOVA model to display the results, and all group differences of the LSM were tested by the Tukey-Kramer procedure. The SLICE statement of the MIXED procedure was used to assess partitioned analyses of the LSM for interactions. Differences with $P<0.05$ were considered significant. The CORR procedure of SAS was used to calculate Pearson correlations between data on the inflammatory response in liver and blood plasma.

\section{RESULTS}

\section{Fatty Acids in Blood Plasma}

The complete data for plasma FA concentrations and the FA composition of plasma fat are shown in Figure 1A-H and in Supplemental Tables S3 and S4 (https:/ /doi.org/10.3168/jds.2020-18735). The concentrations of ALA, EPA, and DPA in plasma fat (equal to all lipids in blood plasma) increased (EFA $\times$ time: $P<$ $0.001)$ with EFA supplementation and were higher $(P$ $<0.001$ ) in both EFA groups than in CTRL across the entire study (Figure 1A-C). Plasma concentration of ALA was higher $(P<0.05)$ in EFA+CLA than in EFA on $\mathrm{d}-42$ ap and $56 \mathrm{pp}$. Plasma EPA was lower $(P<$ $0.05)$ on d $28 \mathrm{pp}$ and plasma DPA was lower $(P<0.05)$ on $\mathrm{d} 1 \mathrm{pp}$ in EFA+CLA than in EFA. Plasma DHA did not change before calving and was higher $(P<0.05)$ in EFA than in CTRL on d 1 pp, higher $(P<0.05)$ in EFA than in all other groups on $\mathrm{d} 28 \mathrm{pp}$, and higher $(P<0.05)$ in EFA+CLA than in EFA and CTRL on d 56 pp.

The plasma concentration of LA dropped toward calving, and continuously increased during early lactation (time: $P<0.001$ ) in all groups (Figure $1 \mathrm{E}$ ). On d 28 pp, plasma LA was higher in CLA than in CTRL and EFA $(P<0.05)$. The concentration of ARA in plasma fat was lower $(P<0.05)$ in both EFA groups than in CTRL and in CLA across the entire study (Figure $1 \mathrm{~F}$ ). Plasma concentrations of both CLA isomers were higher $(P<0.05)$ in CLA and EFA+CLA than in CTRL and EFA across the entire study (Figure $1 \mathrm{G}$ and $\mathrm{H})$. Moreover, plasma cis-9,trans-11 CLA was higher $(P$ $<0.05)$ in CLA than in EFA+CLA on d -42 ap, d 28 $\mathrm{pp}$, and d $56 \mathrm{pp}$.

\section{Lipid Fractions in Plasma}

Cholesterol esters were the greatest lipid fraction in plasma fat (Figure 2A). Plasma FFA and PL proportions increased from $\mathrm{d}-42$ ap to $\mathrm{d} 1 \mathrm{pp}$ and then dropped again (time: $P<0.001$; Figure $2 \mathrm{~B}$ and $\mathrm{C}$ ). The proportion of TG in plasma was highest in all groups during gestation and dropped toward calving $(P<0.001$; Figure 2D). At $\mathrm{d}-42$ ap, the proportion of TG in plasma was higher in CLA than in the all other groups $(P<0.05)$.

\section{Fatty Acids in Lipid Fractions}

The complete data for FA composition in the plasma lipid fractions of CE, FFA, PL, and TG are shown in Supplemental Tables S5-S8 (https://doi.org/10.3168/ jds.2020-18735). The concentration of ALA was higher $(P<0.05)$ in EFA and EFA+CLA than in CTRL and CLA in almost all measurements of the lipid fractions (Figures 3A, 4A, 5A, and 6A). The concentration of ALA was higher $(P<0.05)$ in EFA+CLA than in EFA in $\mathrm{CE}(\mathrm{d}-42$ ap and $\mathrm{d} 56 \mathrm{pp})$ and in TG (d $56 \mathrm{pp}$ ). The concentration of EPA was higher $(P<0.05)$ in both EFA treatments than in CTRL and CLA in CE and PL across the entire study (Figures $3 \mathrm{~B}$ and $5 \mathrm{~B}$ ). In the TG fraction, EPA was higher $(P<0.05)$ in EFA+CLA than in CLA and CTRL at d 56 pp (Figure $6 \mathrm{~B})$. The concentration of DPA in lipid fractions was only markedly increased $(P<0.05)$ in PL of the EFA 

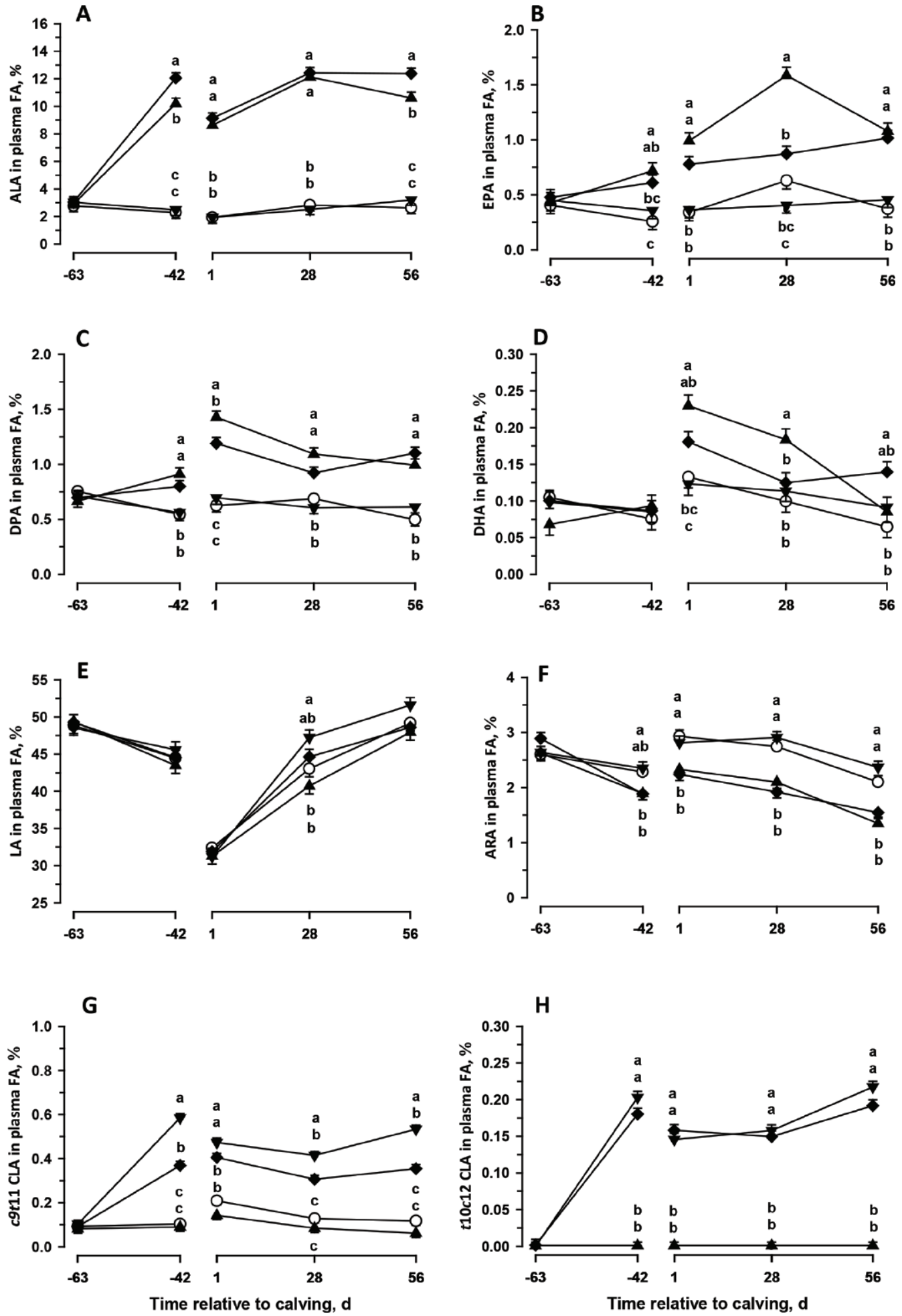

Figure 1. (A) Plasma concentrations of $\alpha$-linolenic acid (ALA), (B) eicosapentaenoic acid (EPA), (C) docosapentaenoic acid (DPA), (D) docosahexaenoic acid (DHA), (E) linoleic acid (LA), (F) arachidonic acid (ARA), (G) cis-9,trans-11 CLA (c9,t11 CLA), and (E) trans-10,cis-12 CLA $(t 10, c 12$ CLA) from 9 wk before until 8 wk after calving in cows supplemented daily with coconut oil $(O \mathrm{CTRL}$; $\mathrm{n}=9)$, linseed and safflower oil $(\boldsymbol{\Delta}$ EFA; $\mathrm{n}=9$ ), Lutalin ( $\boldsymbol{\nabla}$ CLA c9, t11 and $t 10, c 12 ; \mathrm{n}=10$; BASF, Ludwigshafen. Germany), or EFA+CLA $(\bullet ; \mathrm{n}=10)$ from wk 9 antepartum until wk 8 postpartum. Data are presented as the LSM \pm SE. Values with different lowercase letters (a-c) indicate significant differences $(P<0.05)$ among treatments at the respective time point. Statistically significant effects $(P<0.05)$ were observed for EFA treatment [all fatty acids (FA) except $t 10, c 12$ CLA], CLA treatment (ALA; LA; $c 9, t 11$ CLA; $t 10, c 12$ CLA), EFA $\times$ CLA interaction ( $c 9, t 11$ CLA), time (all FA), EFA $\times$ time (all FA except LA and $t 10, c 12$ CLA), and CLA $\times$ time (all FA except ARA). 

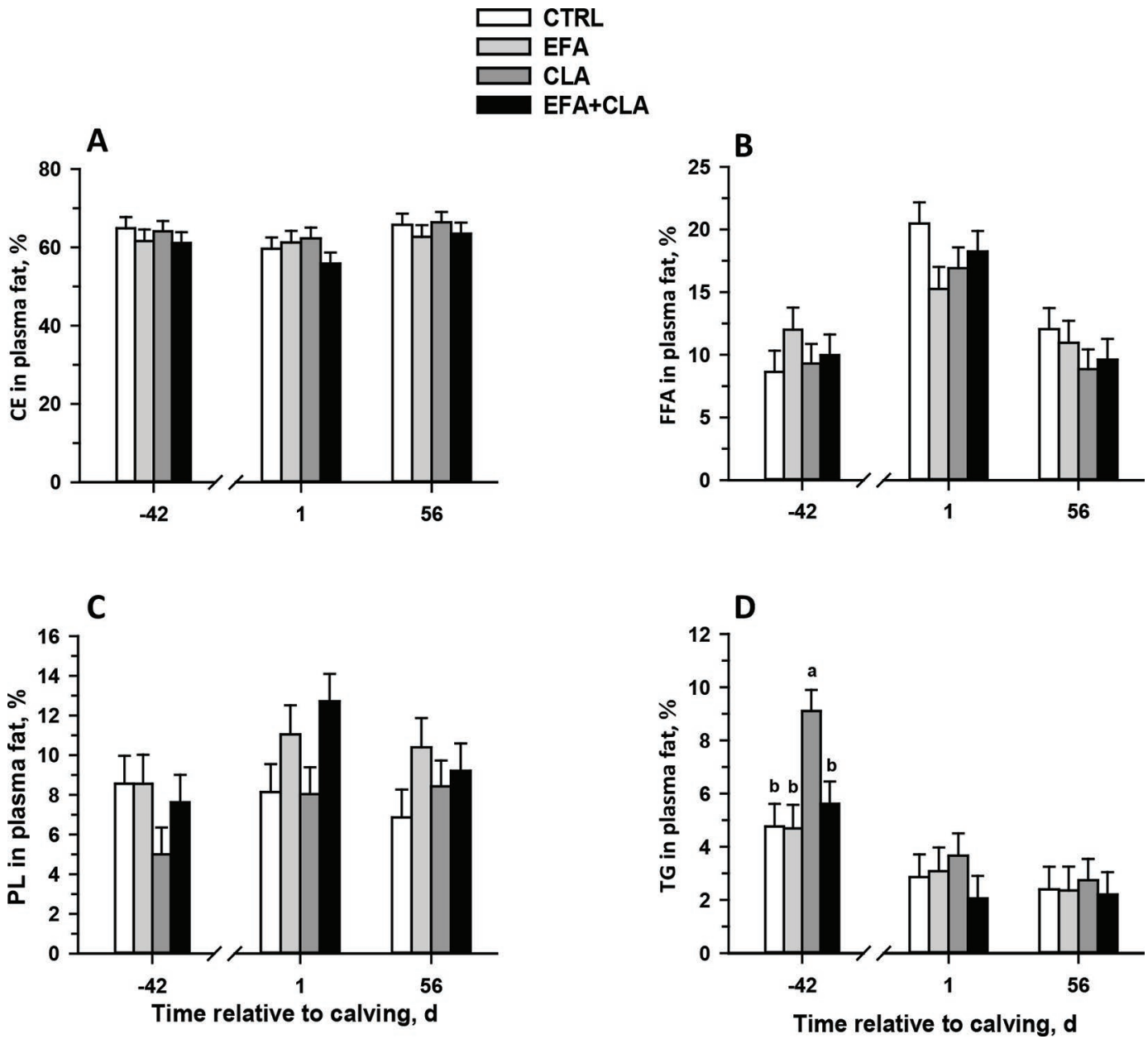

Figure 2. (A) Plasma concentrations of cholesterol esters (CE), (B) free fatty acids (FFA), (C) phospholipids (PL), and (D) triglycerides (TG) on d -42 before calving and d 1 and 56 after calving in cows supplemented with coconut oil (CTRL), linseed and safflower oil (EFA), Lutalin (CLA cis-9,trans-11 and trans-10,cis-12; BASF, Ludwigshafen, Germany), or EFA+CLA. Data are presented as the LSM \pm SE. Values with different lowercase letters $(\mathrm{a}, \mathrm{b})$ indicate significant differences $(P<0.05)$ among treatments at the respective time point. Statistically significant effects $(P<0.05)$ were observed for time (all fatty acids) and for CLA $\times$ time (PL and TG).

and EFA+CLA groups across the entire study (Figure $5 \mathrm{C})$. The proportion of DHA in PL was higher $(P<$ 0.05) in EFA than in CTRL and CLA on d 1 pp, and higher in EFA+CLA than in CTRL on d 56 pp (Figure $5 \mathrm{D})$.

The LA proportion in EFA-treated groups was lower $(P<0.05)$ in $\mathrm{CE}$ on $\mathrm{d}-42$ ap and $56 \mathrm{pp}$, but was higher $(P<0.05)$ in PL on d 56 pp than in non-EFAtreated groups (Figures $3 \mathrm{E}$ and $5 \mathrm{E}$ ). In TG, LA was higher $(P<0.05)$ in EFA+CLA than in EFA on d 56 pp (Figure $6 \mathrm{E})$. The proportion of ARA was lower $(P$ $<0.05)$ in EFA-treated groups than non-EFA-treated groups across the entire study in $\mathrm{CE}$ and on $\mathrm{d} 1$ and 56 pp in PL (Figures $3 \mathrm{~F}$ and $5 \mathrm{~F}$ ). In TG, ARA was higher $(P<0.05)$ in CLA than in CTRL on d 56 pp (Figure $6 \mathrm{~F})$. Concerning CLA isomers in lipid fractions, cis9,trans-11 CLA in CE was higher $(P<0.05)$ in CLA than in CTRL across the entire study (Figure 3G). In PL, cis-9,trans-11 CLA was higher $(P<0.05)$ in both CLA-treated groups than in non-CLA groups across the entire study, and was higher $(P<0.05)$ in CLA than in EFA+CLA on $\mathrm{d}-42$ ap and 56 pp (Figure 5G). In TG, cis-9,trans-11 CLA was higher $(P<0.05)$ in CLA-treated than non-CLA-treated groups on $\mathrm{d}-42$ ap and d $56 \mathrm{pp}$ (Figure 6G). The trans-10,cis-12 CLA was only detectable in $\mathrm{CE}$ and was higher $(P<0.05)$ in CLA-treated than in non-CLA-treated groups across the entire study (Figure $3 \mathrm{H}$ ).

\section{Fatty Acids in EM}

The complete data on FA in EM are shown in Supplemental Table S9 (https://doi.org/10.3168/jds.2020 -18735). The EFA treatment $(P<0.001)$ increased 

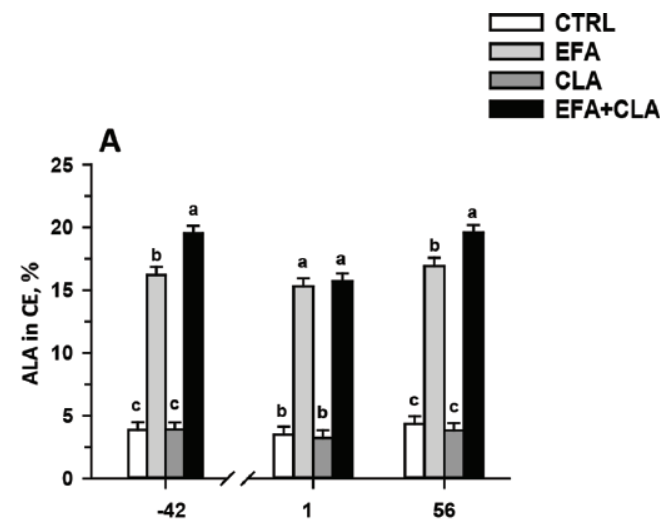

B
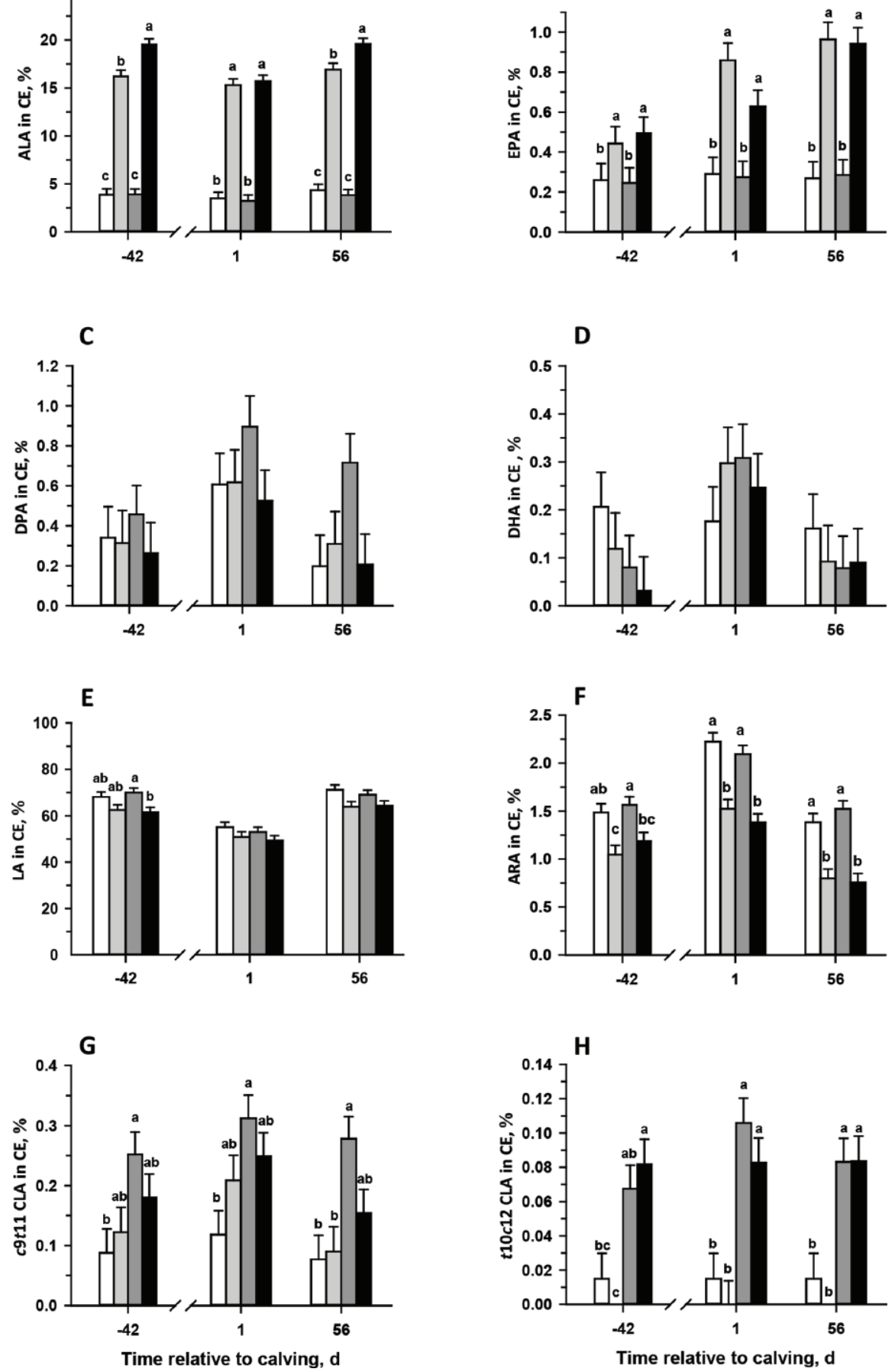

Figure 3. Fatty acid concentrations in plasma cholesterol ester (CE): (A) $\alpha$-linolenic acid (ALA), (B) eicosapentaenoic acid (EPA), (C) docosapentaenoic acid (DPA), (D) docosahexaenoic acid (DHA), (E) linoleic acid (LA), (F) arachidonic acid (ARA), (G) cis-9,trans-11 CLA $(c 9, t 11$ CLA), and $(\mathrm{H})$ trans-10,cis-12 CLA ( $t 10, c 12$ CLA) on d -42 before calving and $\mathrm{d} 1$ and 56 after calving in cows supplemented with coconut oil (CTRL), linseed and safflower oil (EFA), Lutalin (CLA $c 9, t 11$ and $t 10, c 12$; BASF, Ludwigshafen, Germany), or EFA+CLA. Data are presented as the LSM $\pm \mathrm{SE}$. Values with different lowercase letters $(\mathrm{a}-\mathrm{c})$ indicate significant differences $(P<0.05)$ among treatments at the respective time point. Statistically significant effects $(P<0.05)$ were observed for EFA treatment (ALA, EPA, LA, ARA), CLA treatment $(\mathrm{ALA} ; c 9, t 11 \mathrm{CLA} ; t 10, c 12 \mathrm{CLA}), \mathrm{EFA} \times \mathrm{CLA}$ interaction (ALA; DPA; $c 9, t 11 \mathrm{CLA}$ ), time (all fatty acids except $t 10, c 12 \mathrm{CLA})$, and EFA $\times$ time (ALA, EPA, ARA) 

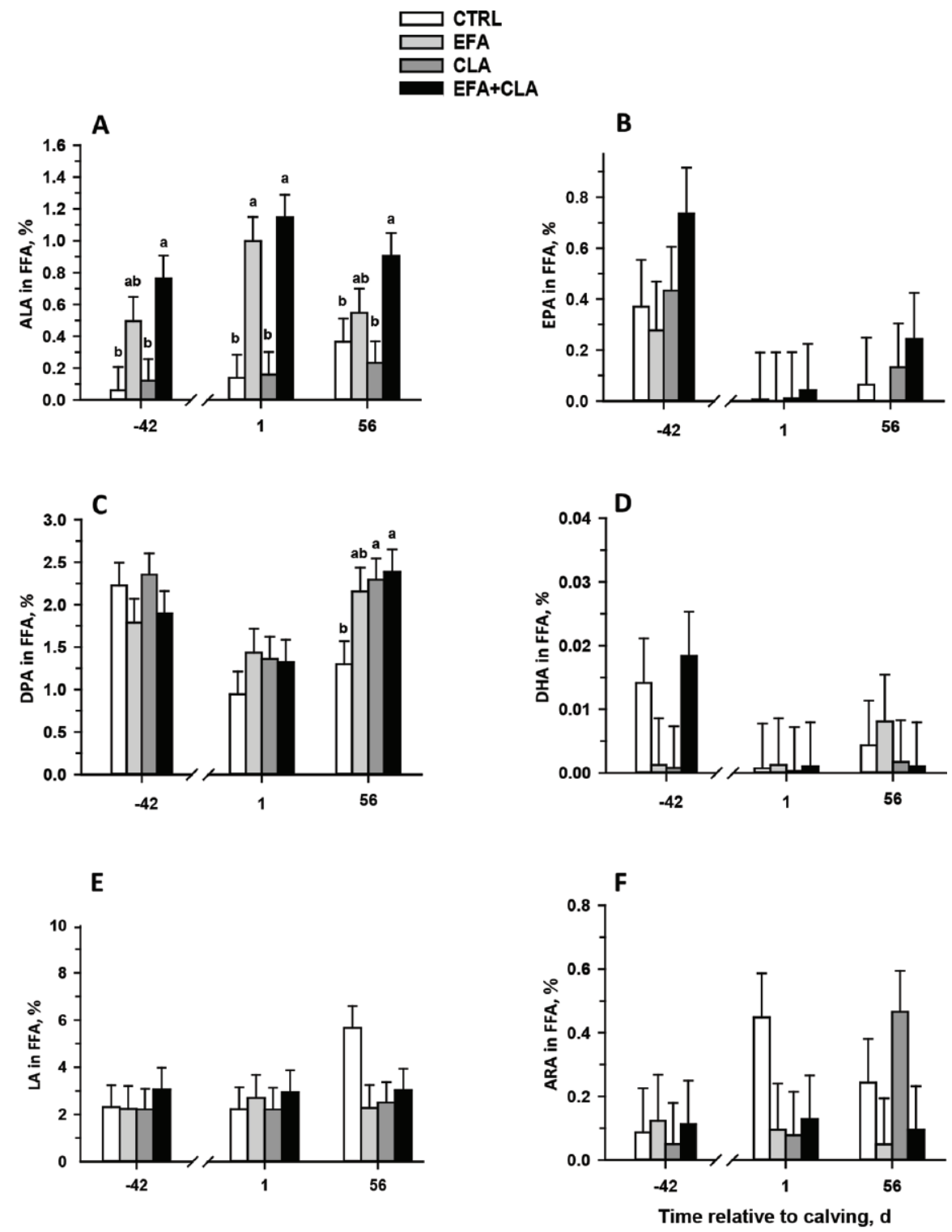

G

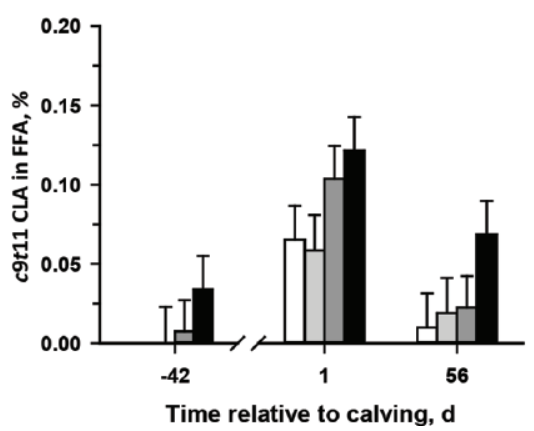

Figure 4. Fatty acid concentrations in plasma free fatty acids (FFA): (A) $\alpha$-linolenic acid (ALA), (B) eicosapentaenoic acid (EPA), (C) docosapentaenoic acid (DPA), (D) docosahexaenoic acid (DHA), (E) linoleic acid (LA), (F) arachidonic acid (ARA), and (G) cis-9,trans-11 CLA ( $c 9, t 11$ CLA) on d -42 before calving and d 1 and 56 after calving in cows supplemented with coconut oil (CTRL), linseed and safflower oil (EFA), Lutalin (CLA $c 9, t 11$ and $t 10, c 12$; BASF, Ludwigshafen, Germany), or EFA+CLA. Data are presented as the LSM \pm SE. Values with different lowercase letters $(\mathrm{a}, \mathrm{b})$ indicate significant differences $(P<0.05)$ among treatments at the respective time point. Statistically significant effects $(P<0.05)$ were observed for EFA treatment (ALA), CLA treatment $(c 9, t 11$ CLA), time (ALA; EPA; DPA; $c 9, t 11$ CLA), and EFA $\times$ time (ALA, DPA). 

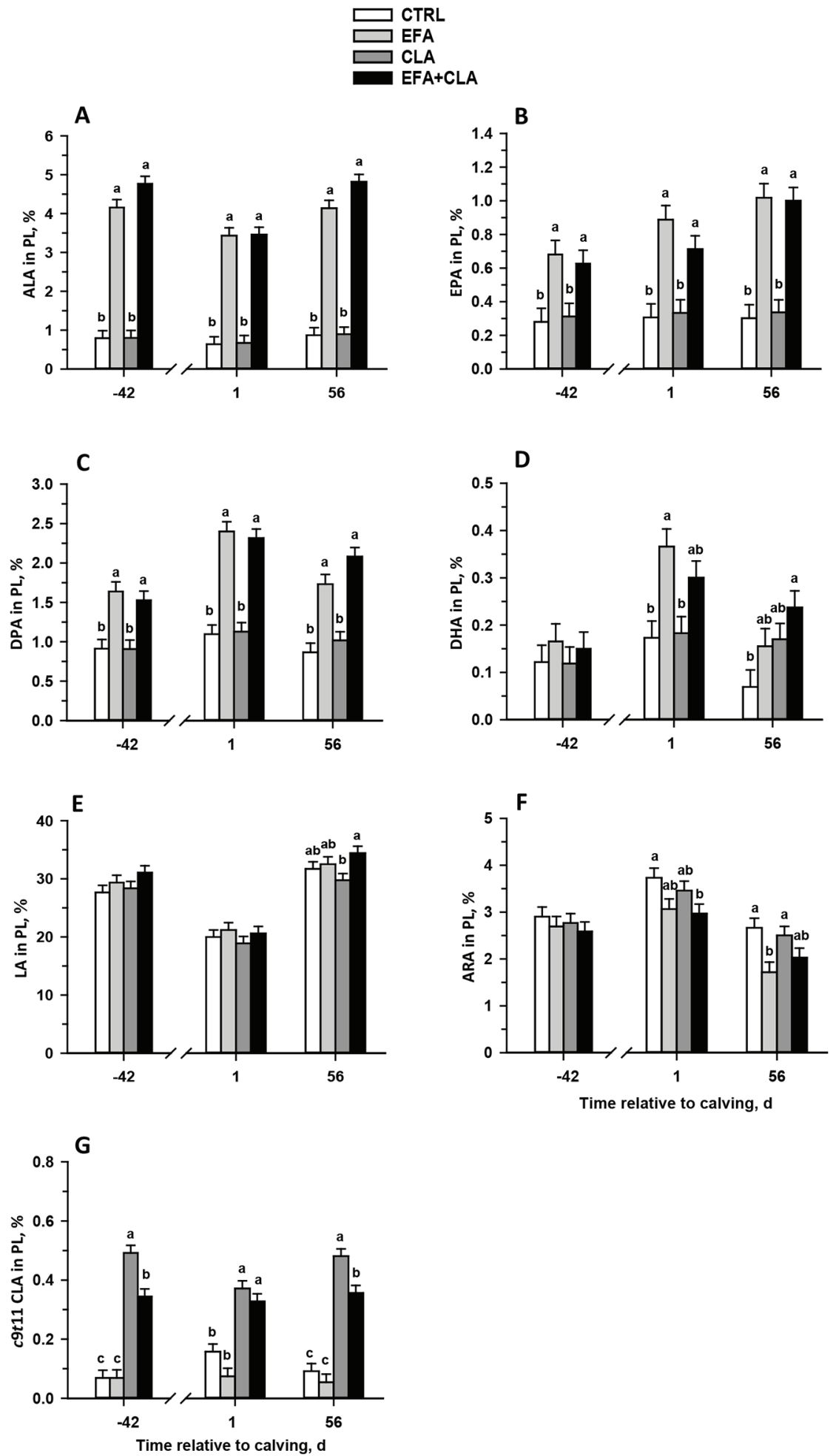

Figure 5. Fatty acid concentrations in phospholipids (PL): (A) o-linolenic acid (ALA), (B) eicosapentaenoic acid (EPA), (C) docosapentaenoic acid (DPA), (D) docosahexaenoic acid (DHA), (E) linoleic acid (LA), (F) arachidonic acid (ARA), and (G) cis-9,trans-11 CLA (c9,t11 CLA) on d -42 before calving and d 1 and 56 after calving in cows supplemented with coconut oil (CTRL), linseed and safflower oil (EFA), Lutalin (CLA $c 9, t 11$ and $t 10, c 12$; BASF, Ludwigshafen, Germany), or EFA+CLA. Data are presented as the LSM \pm SE. Values with different lowercase letters $(\mathrm{a}-\mathrm{c})$ indicate significant differences $(P<0.05)$ among treatments at the respective time point. Statistically significant effects $(P<0.05)$ were observed for EFA treatment (all fatty acids), CLA treatment $(c 9, t 11$ CLA), time (all fatty acids except $c 9, t 11$ CLA), EFA $\times$ time (all n-3 fatty acids), and CLA $\times$ time (DHA; $c 9, t 11$ CLA). 

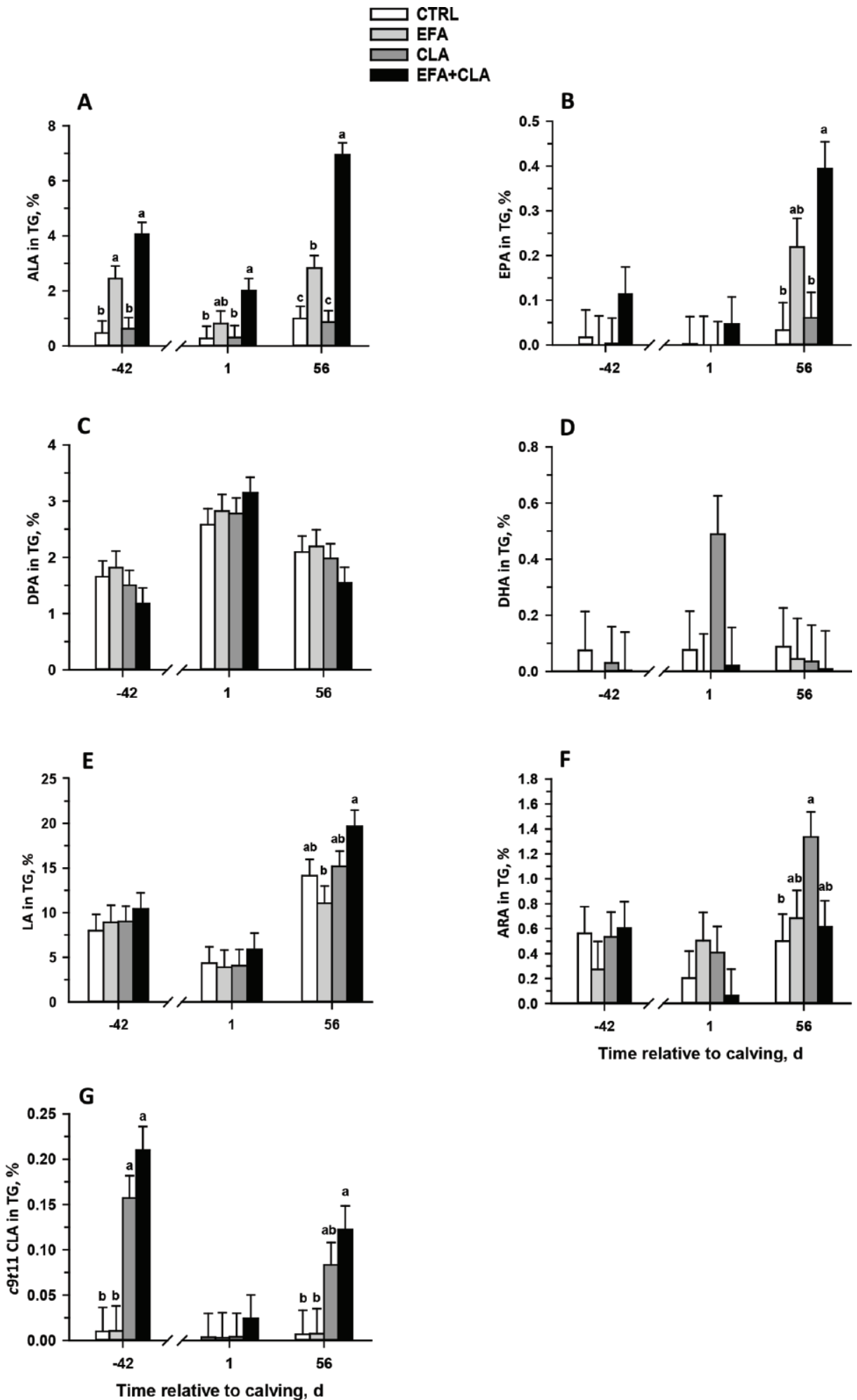

Figure 6. Fatty acid concentrations in triglycerides (TG): (A) $\alpha$-linolenic acid (ALA), (B) eicosapentaenoic acid (EPA), (C) docosapentaenoic acid (DPA), (D) docosahexaenoic acid (DHA), (E) linoleic acid (LA), (F) arachidonic acid (ARA), and (G) cis-9, trans-11 CLA (c9,t11 CLA) on d -42 before calving and d 1 and 56 after calving in cows supplemented with coconut oil (CTRL), linseed and safflower oil (EFA), Lutalin (CLA $c 9, t 11$ and $t 10, c 12$; BASF, Ludwigshafen, Germany), or EFA+CLA. Data are presented as the LSM \pm SE. Values with different lowercase letters $(\mathrm{a}-\mathrm{c})$ indicate significant differences $(P<0.05)$ among treatments at the respective time point. Statistically significant effects $(P<0.05)$ were observed for EFA treatment (ALA, EPA), CLA treatment (ALA; $c 9, t 11$ CLA), EFA $\times$ CLA (ALA), time (all fatty acids except $\mathrm{DHA}), \mathrm{EFA} \times$ time $(\mathrm{ALA}, \mathrm{EPA})$, and $\mathrm{CLA} \times$ time $(\mathrm{ALA} ; \mathrm{DPA} ; c 9, t 11 \mathrm{CLA})$. 

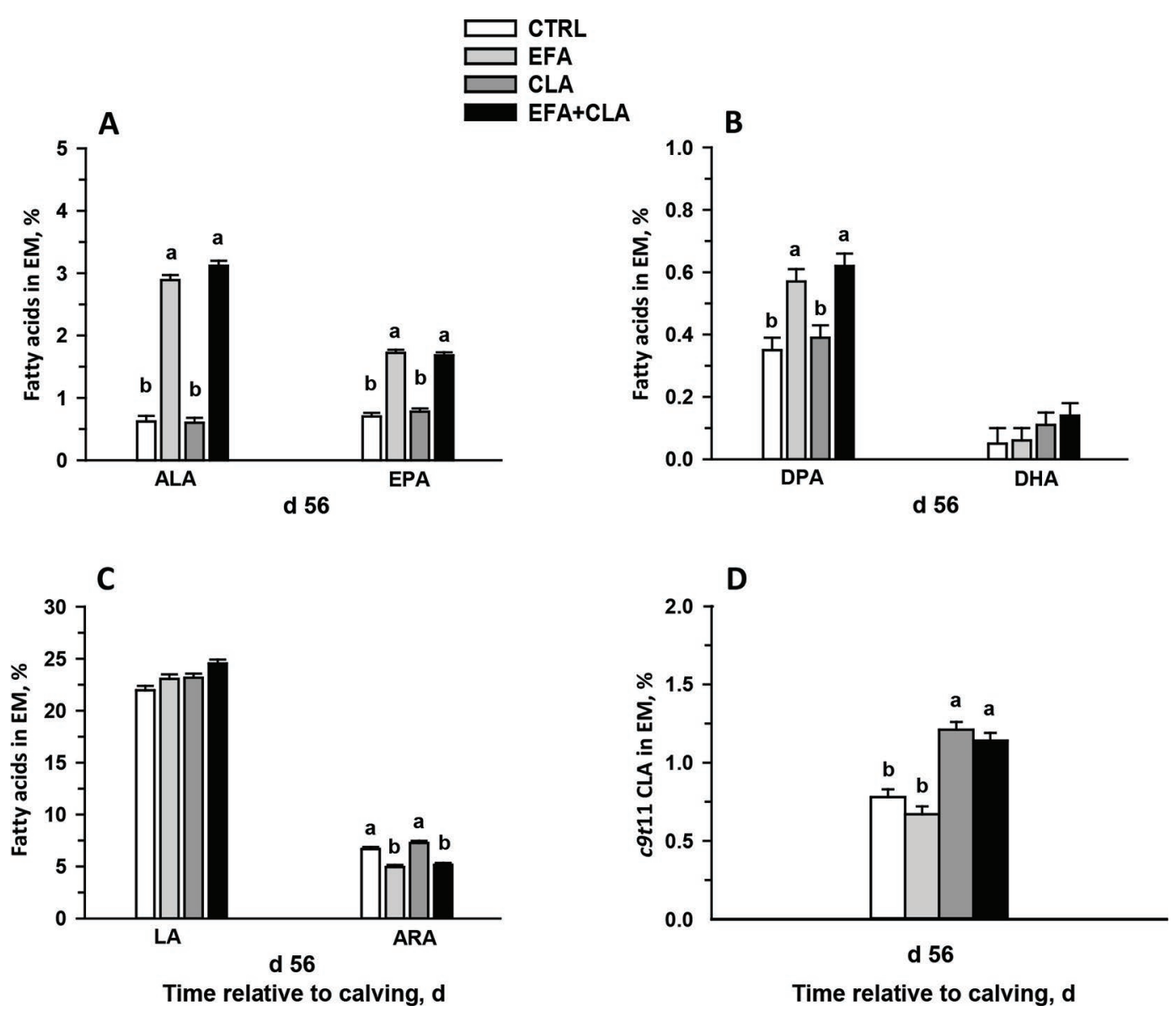

Figure 7. Fatty acid concentrations in erythrocyte membrane (EM): (A) $\alpha$-linolenic acid and eicosapentaenoic acid (ALA, EPA), (B) docosapentaenoic acid and docosahexaenoic acid (DPA, DHA), (C) linoleic acid and arachidonic acid (LA, ARA), and (D) cis-9,trans-11 CLA (c9,t11 CLA) on d 56 after calving in cows supplemented with coconut oil (CTRL), linseed and safflower oil (EFA), Lutalin (CLA $c 9, t 11$ and $t 10, c 12$; BASF, Ludwigshafen, Germany), or EFA+CLA. Data are presented as the LSM \pm SE. Values with different lowercase letters (a, b) indicate significant differences $(P<0.05)$ among treatments at the respective time point. Statistically significant effects $(P<0.05)$ were observed for EFA treatment (ALA, EPA, DPA, LA, ARA), CLA treatment (ARA; $c 9, t 11$ CLA), and EFA × CLA (ALA).

concentrations of ALA and its metabolites (EPA and DPA) in EM (Figures 7A and 7B). Concentration of ARA was lower $(P<0.001)$ in EFA-treated than in non-EFA-treated cows $(P<0.001$, Figure $7 \mathrm{C})$. Concentration of cis-9,trans-11 CLA was higher $(P<0.001)$ in CLA-treated than non-CLA-treated cows (Figure 7D); trans-10,cis-12 CLA was not detected in EM.

\section{Indicators of Inflammation and Hepatic Function in Blood Plasma}

Plasma haptoglobin concentration peaked in all groups around calving $(P<0.001)$. Plasma haptoglobin was lowered $(P<0.05)$ by EFA treatment ap, was higher $(P<0.05)$ in CTRL than in EFA+CLA on $\mathrm{d}$ $-21 \mathrm{ap}$, and tended to be higher $(P=0.08)$ in CTRL than in EFA on $d-35$ and -21 ap (Figure $8 \mathrm{~A}$ ). The plasma concentration of fibrinogen was slightly reduced ap in both CLA-treated groups after the initiation of supplementation compared with EFA $($ EFA $\times$ CLA and CLA $\times$ time; $P<0.05$; Figure $8 \mathrm{~B})$. Plasma fibrinogen was highest on $\mathrm{d} 1 \mathrm{pp}$, and then decreased $(P<0.05)$ in all groups, except in EFA. In EFA, the highest fibrinogen concentration was observed on d 14 pp. Plasma fibrinogen was lower $(P<0.01)$ in CLA than in EFA and EFA+CLA on d 14 pp. The plasma paraoxonase concentration decreased toward calving and then increased after calving in all groups (time; $P<0.001$; Figure 8C). Plasma paraoxonase tended to be affected by EFA treatment $(P=0.08)$. On d $49 \mathrm{pp}$, the paraoxonase concentration was higher $(P<0.05)$ in EFA +CLA than in CTRL. A tendency toward higher paraoxonase concentrations in EFA+CLA compared with CTRL remained until d $56 \mathrm{pp}(P=0.07)$. The plasma bilirubin concentration was low before calving, markedly increased within a week after parturition, and 
A

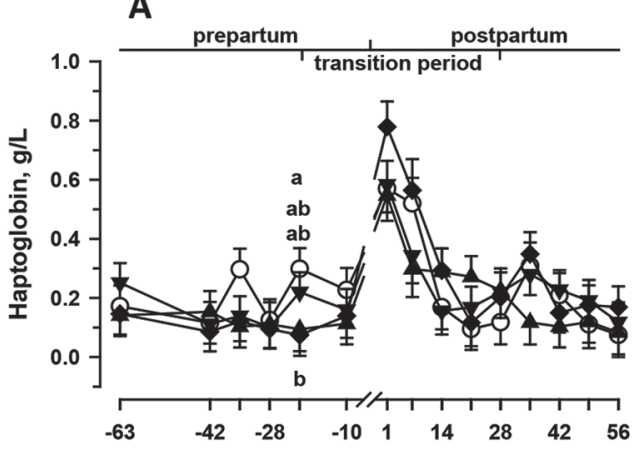

C

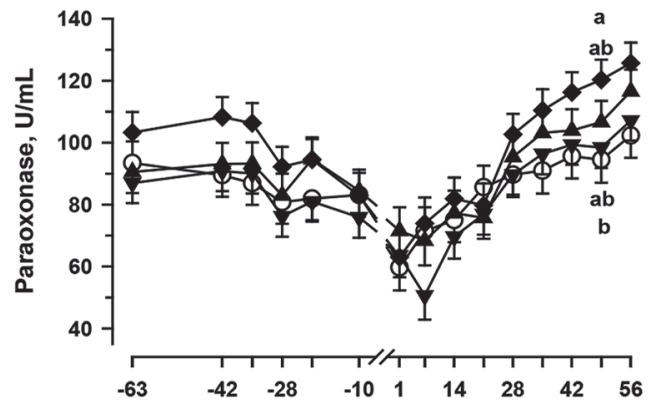

$\mathbf{E}$

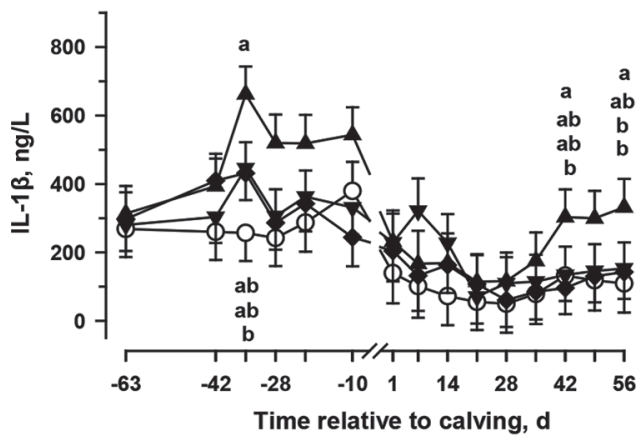

B

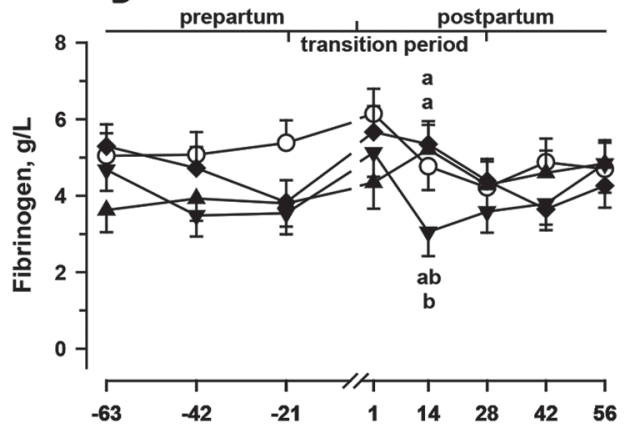

D

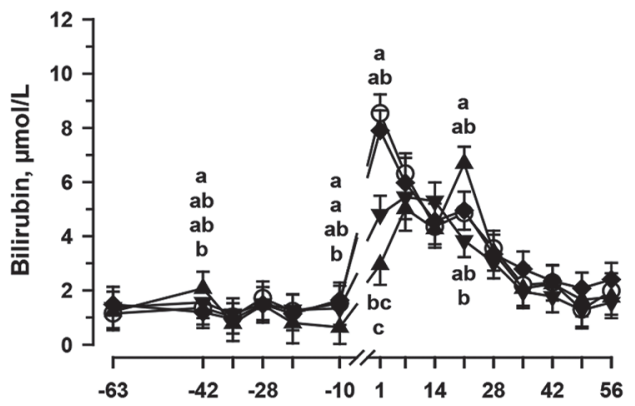

$\mathbf{F}$

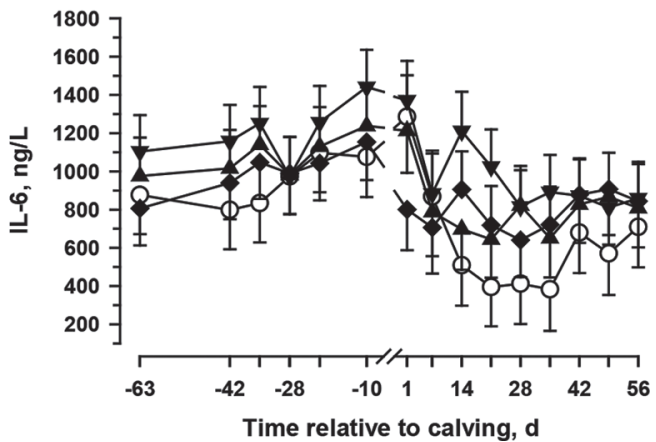

Figure 8. Plasma concentrations of (A) haptoglobin, (B) fibrinogen, (C) paraoxonase, (D) bilirubin, (E) IL-13, and (F) IL-6 from 9 wk before until 8 wk after calving in cows supplemented daily with coconut oil ( $\bigcirc$ CTRL; $\mathrm{n}=9$ ), linseed and safflower oil $(\boldsymbol{\Delta}$ EFA; $\mathrm{n}=9$ ), Lutalin $(\boldsymbol{\nabla}$ CLA cis-9,trans-11 and trans-10,cis-12; $\mathrm{n}=10 ; \mathrm{BASF}$, Ludwigshafen, Germany), or EFA+CLA $(\bullet ; \mathrm{n}=10)$ from wk 9 antepartum until wk 8 postpartum. Data are presented as the LSM \pm SE. Values with different lowercase letters $(\mathrm{a}-\mathrm{c})$ indicate significant differences $(P<0.05)$ among treatments at the respective time point. Statistically significant $(P \leq 0.05)$ effects for haptoglobin concentration during antepartum (EFA), transition (time), postpartum (time), and during the entire study (time). Statistically significant $(P \leq 0.05)$ effects for fibrinogen concentration during antepartum $(\mathrm{EFA} \times \mathrm{CLA}$; CLA $\times$ time), transition $(\mathrm{EFA} \times \mathrm{CLA}$; time; EFA $\times$ time), postpartum (time), and during the entire study (time). Statistically significant $(P \leq 0.05)$ effects for paraoxonase concentration during antepartum (time; CLA $\times$ time), transition (time), postpartum (time; EFA $\times$ time), and during the entire study (time). Statistically significant $(P \leq 0.05)$ effects for bilirubin concentration during antepartum (time; EFA $\times$ CLA $\times$ time), transition $(\mathrm{EFA} \times \mathrm{CLA}$; time; $\mathrm{EFA} \times \mathrm{CLA} \times$ time), postpartum $(\mathrm{EFA} \times \mathrm{CLA}$; time; $\mathrm{EFA} \times \mathrm{CLA} \times$ time), and during the entire study $(\mathrm{EFA} \times \mathrm{CLA}$; time; EFA $\times$ CLA $\times$ time). Statistically significant $(P \leq 0.05)$ effects for IL-1 $\beta$ concentration during antepartum (time), transition (time), postpartum (time; CLA $\times$ time), and during the entire study (time). Statistically significant $(P \leq$ 0.05) effects for IL-6 concentration during antepartum (time), transition (time), postpartum (time), and during the entire study (time).

then gradually decreased in all groups (time; $P<0.001$ Figure 8D). Plasma bilirubin was higher $(P<0.05)$ in EFA than EFA+CLA on $\mathrm{d}-42$ ap, but higher $(P<$
0.05) in EFA+CLA and CTRL compared with EFA on $\mathrm{d}-10$ ap. Plasma bilirubin was lower $(P<0.001)$ in EFA and CLA than in CTRL, and was lower $(P<$ 
0.05) in EFA than in EFA+CLA on d 1 pp. Plasma bilirubin was higher $(P<0.01)$ on d 21 pp in EFA than in CLA. Plasma concentrations of IL-1 $\beta$ and IL-6 decreased after calving $(P<0.001$; Figures $8 \mathrm{E}$ and $8 \mathrm{~F})$. Plasma IL-1 $\beta$ was higher $(P<0.05)$ in EFA than in CTRL on $\mathrm{d}-35$ ap (trend remained on $\mathrm{d}-28$ ap, $P$ $=0.09$ ). Another trend was observed on $\mathrm{d}-10$ ap for higher concentrations in EFA than in EFA +CLA $(P=$ 0.05). Plasma IL-1 $\beta$ was higher $(P<0.05)$ in EFA than in EFA +CLA on d 42 and was higher $(P<0.05)$ in EFA than in EFA+CLA and CTRL on d 56 pp.

Correlations among plasma concentrations of inflammatory traits in blood plasma are presented in Supplemental Table S10 (https://doi.org/10.3168/jds .2020-18735). Plasma concentration of paraoxonase was positively related to the plasma concentration of fibrinogen $(\mathrm{r}=0.26 ; P<0.001)$ and was negatively related to the plasma concentration of haptoglobin and bilirubin $(\mathrm{r}=-0.44$ and $-0.24 ; P<0.001)$. Plasma concentration of IL-1 $\beta$ was positively related to the plasma concentration of IL-6 $(\mathrm{r}=0.41 ; P<0.001)$ and was negatively related to the plasma concentration of fibrinogen and bilirubin $(\mathrm{r}=-0.32$ and $-0.21 ; P<$ 0.001 and $P<0.01$, respectively).

The plasma concentration of $\operatorname{IgG}_{1}$ decreased $(P<$ $0.05)$ from $6.0 \pm 0.3 \mathrm{~g} / \mathrm{L}$ at $\mathrm{d}-63$ ap to $1.9 \pm 0.3 \mathrm{~g} / \mathrm{L}$ at calving, and increased again to $5.3 \pm 0.3 \mathrm{~g} / \mathrm{L}$ at d $56 \mathrm{pp}$ in all groups. The plasma concentration of $\mathrm{IgG}_{2}$ decreased $(P<0.05)$ from $3.6 \pm 0.2 \mathrm{~g} / \mathrm{L}$ at $\mathrm{d}-63$ ap to $2.9 \pm 0.2 \mathrm{~g} / \mathrm{L}$ at $\mathrm{d} 28 \mathrm{pp}$ in all groups. The plasma concentration of IgM decreased $(P<0.05)$ from $2.9 \pm 0.2$ $\mathrm{g} / \mathrm{L}$ at calving to $2.2 \pm 0.2 \mathrm{~g} / \mathrm{L}$ at $14 \mathrm{pp}$ in all groups. Neither EFA nor CLA, nor the combined EFA+CLA treatment affected immunoglobulin concentrations in plasma (Supplemental Figure S1, https://doi.org/10 .3168/jds.2020-18735).

\section{mRNA Abundance of Factors Related to Immune Response and Inflammation in Liver}

Transcript abundances of all investigated genes were affected by time $(P<0.05)$ but not by EFA or CLA treatment (Table 4). The genes encoding the APP HP, $C R P, S A A$, and $F G A$ showed patterns that are typical for the transition period with a rise around calving and lower abundances ap and pp. The mRNA abundance of the HP, CRP, SAA, FGA,IL1A, IL1B, and PON1, as well as COX1 and COX2 mRNA increased on d 63 pp. The abundance of TNFA mRNA showed neither time changes nor group differences. The abundance of $T L R$ 4 mRNA was greater $(P<0.01)$ in the CLA group than in the other groups on $\mathrm{d} 28 \mathrm{pp}$.

Correlations between plasma concentrations of inflammatory traits in blood plasma and liver are pre- sented in Supplemental Table S10 (https://doi.org/10 .3168/jds.2020-18735). Plasma concentration of paraoxonase was positively related to the mRNA abundance of PON1 and $C R P(\mathrm{r}=0.37$ and 0.24 , respectively; $P$ $<0.001$ and $P<0.01$ ), and was negatively related to the mRNA abundance of $S A A$ and $H P(\mathrm{r}=-0.17$ and -0.25 , respectively; $P<0.05$ and $P<0.001)$. In addition, there were weak positive correlations of plasma paraoxonase concentration with mRNA abundance of $I L 1 A$ and $I L 1 B(\mathrm{r}=0.16$ and 0.15 , respectively; $P<$ 0.05). Plasma concentration of haptoglobin was positively related to the mRNA abundance of $H P, S A A$, and $F G A(\mathrm{r}=0.47,0.36$, and 0.25 , respectively; $P<$ 0.001 ). Plasma fibrinogen concentration was positively related to the mRNA abundance of PON1 and CRP (r $=0.22$ and 0.23 , respectively; $P<0.01$ ).

\section{DISCUSSION}

\section{Fatty Acid Profiles in Plasma, Lipid Fractions, and EM}

Changes in the FA pattern in plasma fat due to EFA and CLA infusion corresponded with changes recently published for milk fat (Moallem, 2018; Haubold et al., 2020). A larger increase in ALA induced by the combined EFA+CLA treatment compared with only EFA treatment in plasma fat supported observations in milk fat (Vogel et al., 2020), and was probably the consequence of the reduction in de novo FA synthesis by CLA supplementation (Bauman et al., 2011; Bionaz et al., 2015; Vogel et al., 2020). The LA concentration in plasma fat was only affected on d $28 \mathrm{pp}$ with a higher concentration in the CLA than in the EFA and CTRL groups, highlighting a shift toward low LA in plasma fat as a result of increased middle-chain FA (CTRL) or ALA (EFA) infusion.

The concentrations of n-3 FA metabolites (EPA, DPA, and DHA) increased with EFA treatments, but the increases were lower in plasma fat of EFA+CLAthan EFA-treated cows. These findings may refer to a trans-10, cis-12 CLA-related inhibition of n-3 FA desaturation in dairy cows (Harvatine and Bauman, 2011; Haubold et al., 2020), and support recent findings in milk fat (Vogel et al., 2020). The ARA concentration in plasma fat was lower in EFA and EFA+CLA than in CTRL and CLA due to the shift from n-6 to n-3 FA with the EFA treatments and proposed inhibition of n-6 desaturation (Palmquist, 2010). The increase in cis-9,trans-11 CLA was greater in CLA-treated cows than in EFA+CLA-treated cows. This shift in FA composition was not observed in milk fat (Vogel et al., 2020) and could not be explained by the relative shift of the FA pattern in plasma fat due to the additional 
Gnott et al.: INFLAMMATORY RESPONSE IN COWS AFTER FATTY ACID SUPPLY

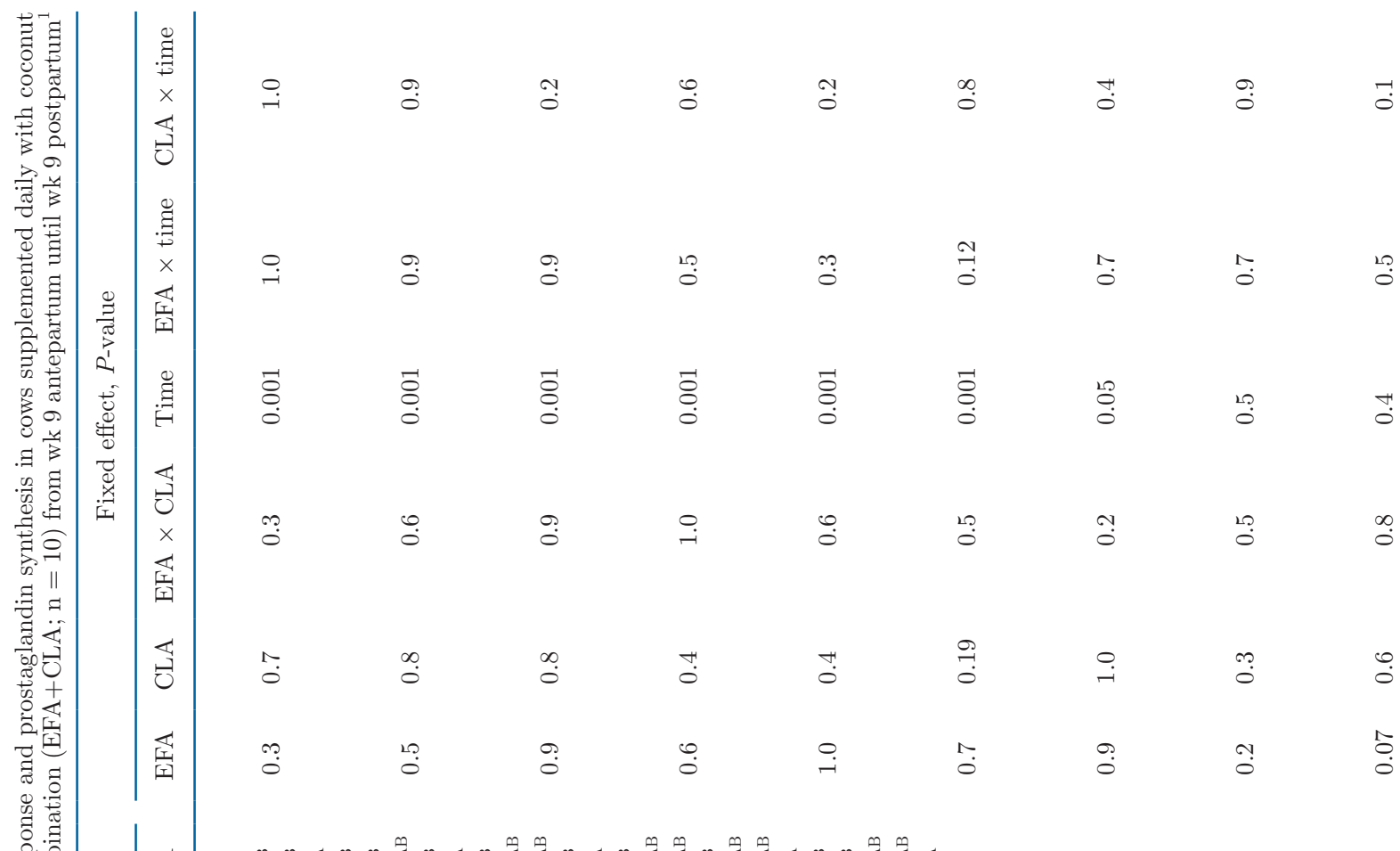

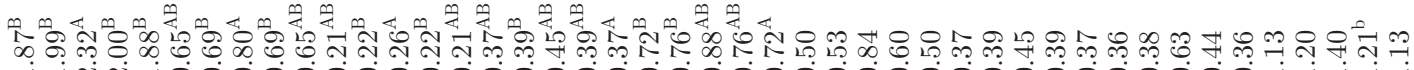
HANT000000000000000000000000000000000007-H $H+H+H+H+H+H+H+H+H+H+H+H+H+H+H+H+H+H+H+H+H+H+H+H+H+H+H+H+H$ 붕의 ง

人 西 $H+H+H+H+H+H+H+H+H+H+H+H+H+H+H+H+H+H+H+H+H+H+H+H+H+H+H+H$

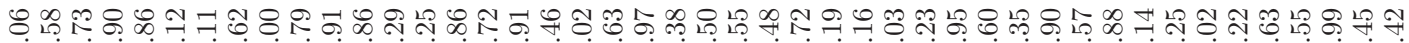

\& i-inti $H+H+H+H+H+H+H+H+H+H+H+H+H+H+H+H+H+H+H+H+H+H+H+H+H+H+H+H$

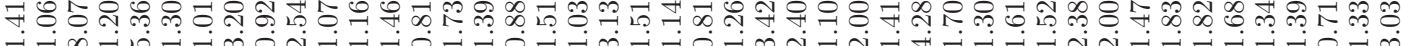

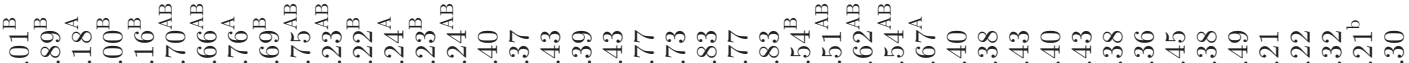
A $H+H+H+H+H+H+H+H+H+H+H+H+H+H+H+H+H+H+H+H+H+H+H+H+H+H+H+H$

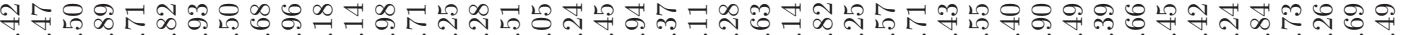

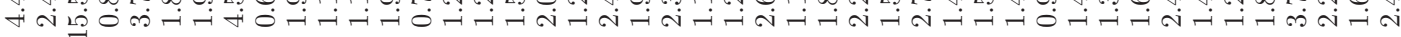

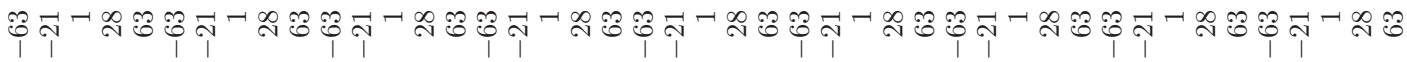

$\vdots$
$\vdots$
2

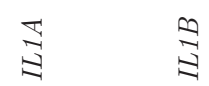

$\underset{\mathrm{Z}}{\mathrm{E}}$

हैं 


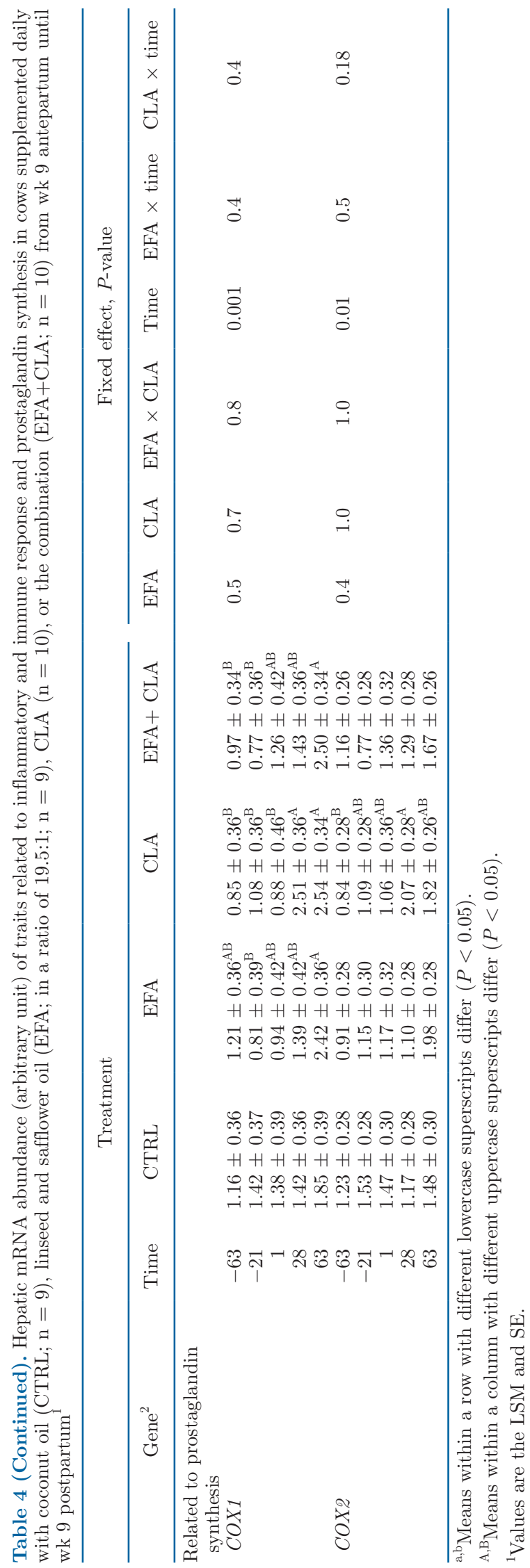

EFA infusion because the absolute concentration of cis-9,trans-11 CLA was also higher in CLA than in EFA+CLA (Supplemental Table S4, https://doi.org/ 10.3168/jds.2020-18735). Therefore, the reason for the differences in cis-9,trans-11 CLA between CLA- and $\mathrm{EFA}+\mathrm{CLA}$-treated cows is currently unknown. In contrast, trans-10,cis-12 CLA did not differ between EFA and EFA+CLA groups in plasma fat.

The different plasma lipid fractions exert distinct functions, and their fluctuations around parturition are connected with increased requirements of substrates for energy production during late gestation and the increased demands of FA for milk fat synthesis (Christie, 1981; Bionaz et al., 2007; Baumgard et al., 2017). In ruminants, most of the PUFA in plasma, especially LA, are localized in the CE and PL fractions, and dietary PUFA that escape rumen degradation are particularly stored in plasma CE and PL (Christie, 1981; Loor and Herbein, 2003; Palmquist, 2010). In fact, our results showed that $\mathrm{CE}$ contained the highest proportion of ALA and LA compared with other lipid fractions. The selective transfer of dietary LA and ALA to specific lipid fractions that do not provide significant amounts of FA to the mammary gland for milk fat production, such as CE and PL, may be a mechanism to store biologically active FA for more essential functions (Noble et al., 1982; Palmquist, 2010). In the present study, EFA and EFA+CLA treatments increased ALA in all lipid fractions because EFA was enriched for ALA. An increase in EPA concentration due to EFA and EFA+CLA treatments was predominantly observed in the PL and CE fractions. Elevated concentrations of DPA and partly of DHA after EFA and EFA+CLA treatment were mainly determined in the PL fraction. In addition, enhanced proportions of ALA, EPA, and DPA were observed in the EM of EFA- and EFA+CLAtreated cows. Cell membranes are rich in PL. Therefore, our study confirmed n-3 FA storage was preferably in the PL fraction of the blood plasma (Barceló-Coblijn and Murphy, 2009; Palmquist, 2010; Moallem, 2018).

Because all cows were fed the same diet with a high LA content, the concentration of LA in the plasma lipid fractions differed to a lesser extent among groups or even was lower in EFA- or EFA+CLA-treated cows. The concentrations of ARA in the CE and PL plasma fractions, as well as EM, were clearly reduced by EFA with or without CLA treatment. In addition to a general shift from n-6 to n-3 FA due to EFA treatment, the lower ARA proportion was probably caused by the inhibition of n- 6 desaturation due to EFA infusion (Palmquist, 2010). An additional inhibitory effect of CLA treatment on $\Delta 6$-desaturase activity, and consequently a reduced conversion of LA to ARA (as assumed in rodents), probably did not occur in the present study 
because ARA proportion in lipid fractions did not differ between CLA and EFA+CLA groups. The CLA dosages used in rodent studies were much higher than in the present study, which may explain our different findings (Belury and Kempa-Steczko, 1997; Park et al., 2001). On the other hand, a higher concentration of LA in TG on d 56 in EFA+CLA than in EFA again indicated a shift toward long-chain FA due to inhibition of de novo FA synthesis caused by CLA (Bauman et al., 2011; Bionaz et al., 2015).

Only the cis-9,trans-11 isomer was measurable in all lipid fractions of the plasma in the present study. In contrast to trans-10,cis-12 CLA, cis-9,trans-11 CLA is endogenously synthesized from vaccenic acid (18:1 trans-11) by $\Delta 9$-desaturase (Griinari et al., 2000). However, mammalian tissue lacks the enzyme $\Delta 12$ desaturase to reconvert trans-10,cis-12 CLA from 18:1 trans-10; such that all of the trans-10, cis-12 CLA detected in plasma seems to originate from gastrointestinal absorption (Pariza et al., 2001). The fact that the plasma FA profile is the first medium to mirror dietary changes, and that $\mathrm{CE}$ represents the greatest fraction of all lipids in plasma, explains why trans-10,cis-12 CLA could only be detected in this compartment. Studies in humans (Burdge et al., 2005) and porcine EM (Malovrh et al., 2014) showed preferential uptake of the cis-9,trans-11 CLA isomer when both cis-9,trans-11 and trans-10,cis-12 CLA were administered in the same doses. This may explain why we could not detect trans10, cis-12 CLA in the EM of the investigated cows.

\section{Systemic and Hepatic Inflammatory Response}

Our results regarding the inflammatory response in blood plasma revealed marked changes in APP and interleukins around calving, indicating a mild to moderate inflammatory reaction, which is commonly observed in the periparturient period (Bertoni et al., 2008; Trevisi et al., 2015; Jawor et al., 2016). The concentrations of haptoglobin and bilirubin decreased, while paraoxonase rose in all groups, probably because of the reduction of metabolic energy load and improvement of liver function after calving. In the present and in previous studies, higher concentrations of IL- $1 \beta$ and IL-6 were collected during pregnancy, and IL-6 and IL$1 \beta$ decreased shortly after parturition (Sordillo et al., 1995; Ishikawa et al., 2004; Trevisi et al., 2015).

Our study revealed significant interactions between EFA and CLA treatments in the transit phase. The EFA treatment lowered the plasma haptoglobin concentration before calving and tended to raise paraoxonase activity throughout supplementation. Paraoxonase belongs to the negative APP and expresses a reverse time pattern during the transition period compared with haptoglobin (Bionaz et al., 2007). Plasma bilirubin is related to the acute phase response (Trevisi et al., 2012), and bilirubinemia was lowest in the EFA group at calving. In previous studies, a milder acute phase response after LPS challenge in n-3 FA-fed cows (Trevisi et al., 2011; Greco et al., 2015) and calves (Ballou et al., 2008) has been described. The findings in the present study may point toward a better recovery after the transition phase in EFA-treated cows (Bertoni et al., 2015). Therefore, our results support the general concept of a reduced inflammatory response in the dairy cow with an elevated n-3 FA and a reduced n-6:n -3 FA status (Lessard et al., 2003; Gandra et al., 2016; Sordillo, 2016).

A higher IL-1 $\beta$ plasma concentration in the EFA group throughout the dry period and after the transition was probably associated with the greater intake of n-3 FA (Lokesh et al., 1990). Given that proinflammatory cytokines stimulate the production of APP (Fleck, 1989; Bertoni and Trevisi, 2013; Trevisi et al., 2015), the fact that a low plasma haptoglobin concentration was paralleled by elevated plasma IL- $1 \beta$ in the present study was not expected. The lower n-6:n-3 FA ratio in blood plasma might have impaired the stimulation of plasma haptoglobin by inhibiting the action of proinflammatory cytokines. Although IL-1 $\beta$ was markedly higher in our EFA group, no stimulating response was noted for the concentration of plasma haptoglobin; however, plasma IL-1 $\beta$ was negatively associated with plasma concentration of fibrinogen, which supports findings in the literature (Bode et al., 2012). The stimulatory effect of IL-1 $\beta$ on haptoglobin production might differ among species and in bovine hepatocytes, IL-1 $\beta$ failed to stimulate haptoglobin synthesis (NakagawaTosa et al., 1995).

Concerning CLA, the cis-9,trans-11 CLA isomer in particular has anti-inflammatory capacities (Viladomiu et al., 2016). Studies in epithelial cells in the bovine mammary gland have indicated reduced gene expression of pro- and anti-inflammatory cytokines after LPS challenge by EFA and CLA (Dipasquale et al., 2018). In the present study, the plasma fibrinogen concentration decreased in the blood plasma of the CLA-treated groups after the onset of supplementation, and plasma fibrinogen was lowest on d $14 \mathrm{pp}$ in CLA-treated cows. In addition, CLA treatment alone reduced the bilirubin increase at calving. It was assumed that part of the CLA effect is based on the modulation of glucose metabolism caused by the reduction in milk fat synthesis in the mammary gland (Hötger et al., 2013). Glucose serves as an important fuel for immune cells, but at the onset of lactation most of the glucose is utilized in the mammary gland for synthesis of lactose (Baumgard et al., 2017; Gross et al., 2018). Measurement of whole glucose 
turnover by $\left[{ }^{13} \mathrm{C}_{6}\right]$ glucose revealed a reduction of the endogenous glucose production and a glucose-sparing effect due to CLA administration in the current study (L. Vogel, M. Gnott, and H. M. Hammon, unpublished observation), which supports previous findings (Hötger et al., 2013). However, inflammatory traits were only marginally affected by CLA treatment, which might indicate that the inflammatory status of the cows was not related to the glucose metabolism in the present study. Previous studies also showed no CLA effects on the inflammatory response during the transition period in dairy cows (Saremi et al., 2012a; Schäfers et al., 2018).

The abundance of genes involved in the acute phase response (HP, SAA, FGA, CRP, and IL1) increased around calving, which is consistent with our plasma results and supported by the literature (Loor et al., 2005). Correlations of mRNA abundance and plasma concentration of haptoglobin and paraoxonase clearly pointed at the importance of their production in liver. Nevertheless, no differences between groups were detected. The elevated mRNA abundance of the APP and COX1 and COX2 on d 63 pp in the liver could be initiated by the acute stress that cows experienced before slaughter (Murata and Miyamoto, 1993; Colditz, 2002).

\section{CONCLUSIONS}

Abomasal infusion of EFA with or without CLA increased the ALA concentration in all measured lipid fractions of the blood plasma. However, n-3 FA metabolites were primarily elevated in the PL fraction, indicating a different distribution of $\mathrm{n}-3$ metabolites among lipid fractions in blood plasma. In addition, n-3 FA were enriched in the EM of EFA-treated cows, supporting the role of $\mathrm{PL}$ in retaining n-3 FA in EM. The combined EFA+CLA treatment partly reduced the enrichment of n-3 FA in blood plasma due to the inhibitory effect of CLA on EFA desaturation. The elevated n-3 FA status and the reduced n-6:n-3 ratio in blood plasma indicated a more distinct anti-inflammatory effect during the transition period in blood plasma than the CLA treatment. The combined EFA+CLA treatment barely showed additional benefits on the regulation of a presumed anti-inflammatory response; therefore, the combined CLA+EFA treatment did not affect the inflammatory response in a synergistic manner in dairy cows around calving in the present study.

\section{ACKNOWLEDGMENTS}

The authors express their gratitude to the staff of the Experimental Animal Facility Cattle and the "Tiertechnikum" of the Leibniz Institute for Farm Animal Biology (FBN; Dummerstorf, Germany) for their contribution to the present study and animal care. We thank Claudia Reiko, Anne Möller, Heike Pröhl, Christa Fiedler, Birgit Jentz, and Maria Dahm (all FBN) for excellent laboratory work, as well as Matthias Kaiser and Anne Kretschmar (Clinic for Ruminants and Swine, Leipzig, Germany) for surgical rumen cannulation. We further acknowledge the cattle breeding association (RinderAllianz GmbH, Woldegk, Germany) and Agrarprodukte Dedelow GmbH (Prenzlau, Germany) for the assortment of cows. The project was supported by BASF SE (Ludwigshafen, Germany) and by funds of the Federal Ministry of Food and Agriculture (BMEL) based on a decision of the Parliament of the Federal Republic of Germany via the Federal Office for Agriculture and Food (BLE) under the innovation support program (grant number 313-06.01-28-1-79.003-15). The authors declare that there are no conflicts of interest.

\section{REFERENCES}

Ballou, M. A., G. D. Cruz, W. Pittroff, D. H. Keisler, and E. J. DePeters. 2008. Modifying the acute phase response of Jersey calves by supplementing milk replacer with omega-3 fatty acids from fish oil. J. Dairy Sci. 91:3478-3487. https://doi.org/10.3168/ jds.2008-1016.

Barceló-Coblijn, G., and E. J. Murphy. 2009. Alpha-linolenic acid and its conversion to longer chain n-3 fatty acids: benefits for human health and a role in maintaining tissue n- 3 fatty acid levels. Prog. Lipid Res. 48:355-374. https://doi.org/10.1016/j.plipres.2009.07 .002 .

Bauman, D., L. Baumgard, B. Corl, and D. J. Griinari. 2000. Biosynthesis of conjugated linoleic acid in ruminants. J. Anim. Sci. 77(E-Suppl):1-15. https://doi.org/10.2527/jas2000.77E-Suppl1f.

Bauman, D. E., K. J. Harvatine, and A. L. Lock. 2011. Nutrigenomics, rumen-derived bioactive fatty acids, and the regulation of milk fat synthesis. Annu. Rev. Nutr. 31:299-319. https://doi.org/10.1146/ annurev.nutr.012809.104648.

Baumgard, L. H., R. J. Collier, and D. E. Bauman. 2017. A 100-year review: Regulation of nutrient partitioning to support lactation. J. Dairy Sci. 100:10353-10366. https://doi.org/10.3168/jds.2017 $-13242$.

Belury, M. A., and A. Kempa-Steczko. 1997. Conjugated linoleic acid modulates hepatic lipid composition in mice. Lipids 32:199-204. https://doi.org/10.1007/s11745-997-0025-0.

Bertoni, G., A. Minuti, and E. Trevisi. 2015. Immune system, inflammation and nutrition in dairy cattle. Anim. Prod. Sci. 55:943-948. https://doi.org/10.1071/AN14863.

Bertoni, G., and E. Trevisi. 2013. Use of the liver activity index and other metabolic variables in the assessment of metabolic health in dairy herds. Vet. Clin. North Am. Food Anim. Pract. 29:413-431. https://doi.org/10.1016/j.cvfa.2013.04.004.

Bertoni, G., E. Trevisi, X. Han, and M. Bionaz. 2008. Effects of inflammatory conditions on liver activity in puerperium period and consequences for performance in dairy cows. J. Dairy Sci. 91:33003310. https://doi.org/10.3168/jds.2008-0995.

Bionaz, M., J. Osorio, and J. J. Loor. 2015. TRIENNIAL LACTATION SYMPOSIUM: Nutrigenomics in dairy cows: Nutrients, transcription factors, and techniques. J. Anim. Sci. 93:5531-5553. https://doi.org/10.2527/jas.2015-9192.

Bionaz, M., E. Trevisi, L. Calamari, F. Librandi, A. Ferrari, and G. Bertoni. 2007. Plasma paraoxonase, health, inflammatory conditions, and liver function in transition dairy cows. J. Dairy Sci. 90:1740-1750. https://doi.org/10.3168/jds.2006-445.

Bode, J. G., U. Albrecht, D. Haussinger, P. C. Heinrich, and F. Schaper. 2012. Hepatic acute phase proteins-regulation by IL-6- 
and IL-1-type cytokines involving STAT3 and its crosstalk with NF-kappaB-dependent signaling. Eur. J. Cell Biol. 91:496-505. https://doi.org/10.1016/j.ejcb.2011.09.008.

Burdge, G. C., P. R. Derrick, J. J. Russell, S. Tricon, S. Kew, T. Banerjee, R. F. Grimble, C. M. Williams, P. Yaqoob, and P. C. Calder. 2005. Incorporation of cis-9, trans-11 or trans-10, cis-12 conjugated linoleic acid into human erythrocytes in vivo. Nutr. Res. 25:13-19. https://doi.org/10.1016/j.nutres.2004.08.002.

Calamari, L., A. Ferrari, A. Minuti, and E. Trevisi. 2016. Assessment of the main plasma parameters included in a metabolic profile of dairy cow based on Fourier transform mid-infrared spectroscopy: Preliminary results. BMC Vet. Res. 12:4. https://doi.org/10.1186/ s12917-015-0621-4 http://dx.doi.org/410.1186/s12917-015-0621-4.

Ceciliani, F., J. J. Ceron, P. D. Eckersall, and H. Sauerwein. 2012. Acute phase proteins in ruminants. J. Proteomics 75:4207-4231. https://doi.org/10.1016/j.jprot.2012.04.004.

Chilliard, Y., A. Ferlay, and M. Doreau. 2001. Effect of different types of forages, animal fat or marine oils in cow's diet on milk fat secretion and composition, especially conjugated linoleic acid (CLA) and polyunsaturated fatty acids. Livest. Prod. Sci. 70:31-48. https: //doi.org/10.1016/S0301-6226(01)00196-8.

Christie, W. W. 1981. The effects of diet and other factors on the lipid composition of ruminant tissues and milk. Pages 125-226 in Lipid Metabolism in Ruminant Animals. W. W. Christie, ed. Pergamon, Pergamon Press, Oxford, UK.

Colditz, I. G. 2002. Effects of the immune system on metabolism: Implications for production and disease resistance in livestock. Livest. Prod. Sci. 75:257-268. https://doi.org/10.1016/S0301 $-6226(01) 00320-7$.

Dannenberger, D., G. Nuernberg, K. Nuernberg, K. Will, N. Schauer, and M. Schmicke. 2017. Effects of diets supplemented with n-3 or n-6 PUFA on pig muscle lipid metabolites measured by non-targeted LC-MS lipidomic profiling. J. Food Compos. Anal. 56:47-54. https://doi.org/10.1016/j.jfca.2016.11.015.

Dannenberger, D., K. Nuernberg, G. Nuernberg, and A. Priepke. 2012. Different dietary protein and PUFA interventions alter the fatty acid concentrations, but not the meat quality, of porcine muscle. Nutrients 4:1237-1246. https://doi.org/10.3390/nu4091237.

Dipasquale, D., L. Basirico, P. Morera, R. Primi, A. Tröscher, and U. Bernabucci. 2018. Anti-inflammatory effects of conjugated linoleic acid isomers and essential fatty acids in bovine mammary epithelial cells. Animal 12:2108-2114. https://doi.org/10.1017/ S1751731117003676.

DLG (Deutsche Landwirtschafts-Gesellschaft, German Agricultural Society). 2013. Leitfaden zur Berechnung des Energiegehaltes bei Einzel-und Mischfuttermitteln für die Schweine-und Rinderfütterung (Guidelines for calculation of energy content of single and mixed feedstuff for pigs and cattle). Stellungnahme des DLG-Arbeitskreises Futter und Fütterung.

Ferlay, A., B. Martin, P. Pradel, J. B. Coulon, and Y. Chilliard. 2006. Influence of grass-based diets on milk fatty acid composition and milk lipolytic system in Tarentaise and Montbeliarde cow breeds. J. Dairy Sci. 89:4026-4041. https://doi.org/10.3168/jds.S0022 $-0302(06) 72446-8$

Ferré, N., J. Camps, E. Prats, E. Vilella, A. Paul, L. Figuera, and J. Joven. 2002. Serum paraoxonase activity: A new additional test for the improved evaluation of chronic liver damage. Clin. Chem. 48:261-268. https://doi.org/10.1093/clinchem/48.2.261.

Fleck, A. 1989. Clinical and nutritional aspects of changes in acutephase proteins during inflammation. Proc. Nutr. Soc. 48:347-354. https://doi.org/10.1079/PNS19890050.

Gandra, J. R., R. V. Barletta, R. D. Mingoti, L. C. Verdurico, J. E. Freitas Jr., L. J. Oliveira, C. S. Takiya, J. R. Kfoury Jr., M. C. Wiltbank, and F. P. Renno. 2016. Effects of whole flaxseed, raw soybeans, and calcium salts of fatty acids on measures of cellular immune function of transition dairy cows. J. Dairy Sci. 99:45904606. https://doi.org/10.3168/jds.2015-9974.

Gerbert, C., D. Frieten, C. Koch, G. Dusel, K. Eder, T. Stefaniak, J. Bajzert, P. Jawor, A. Tuchscherer, and H. M. Hammon. 2018. Effects of ad libitum milk replacer feeding and butyrate supplementation on behavior, immune status, and health of Holstein calves in the postnatal period. J. Dairy Sci. 101:7348-7360. https://doi .org/10.3168/jds.2018-14542.

GfE (German Society of Nutrition Physiology). 2001. Empfehlungen zur Energie- und Nährstoffversorgung der Milchkühe und Aufzuchtrinder [Recommended energy and nutrient supply for dairy cows and heifers]. Ausschuss für Bedarfsnormen der Gesellschaft für Ernährungsphysiologie No. 8. DLG Verlag, Frankfurt am Main, Germany.

GfE (German Society of Nutrition Physiology). 2008. New equations for predicting metabolisable energy of grass and maize products for ruminants. Mitteilung des Ausschusses für Bedarfsnormen der Gesellschaft für Ernährungsphysiologie. Proc. Soc. Nutr. Physiol. 17:191-198.

GfE (German Society of Nutrition Physiology). 2009. New equations for predicting metabolisable energy of compound feeds for cattle. communications of the committee for requirement standards of the society of nutrition physiology. Proc. Soc. Nutr. Physiol. $18: 143-146$

Greco, L. F., J. T. Neves Neto, A. Pedrico, R. A. Ferrazza, F. S. Lima, R. S. Bisinotto, N. Martinez, M. Garcia, E. S. Ribeiro, G. C. Gomes, J. H. Shin, M. A. Ballou, W. W. Thatcher, C. R. Staples, and J. E. Santos. 2015. Effects of altering the ratio of dietary n-6 to n-3 fatty acids on performance and inflammatory responses to a lipopolysaccharide challenge in lactating Holstein cows. J. Dairy Sci. 98:602-617. https://doi.org/10.3168/jds.2014-8805.

Griinari, J. M., B. Corl, S. Lacy, P. Chouinard, K. Nurmela, and D. Bauman. 2000. Conjugated linoleic acid is synthesized endogenously in lactating dairy cows by $\Delta 9$-desaturase. J. Nutr. 130:2285-2291. https://doi.org/10.1093/jn/130.9.2285.

Gross, J. J., L. Grossen-Rosti, R. Heritier, A. Tröscher, and R. M. Bruckmaier. 2018. Inflammatory and metabolic responses to an intramammary lipopolysaccharide challenge in early lactating cows supplemented with conjugated linoleic acid. J. Anim. Physiol. Anim. Nutr. (Berl.) 102:e838-e848. https://doi.org/10.1111/jpn .12843 http://dx.doi.org/:10.1111/jpn.12843.

Harvatine, K. J., and D. E. Bauman. 2011. Characterization of the acute lactational response to trans-10, cis-12 conjugated linoleic acid. J. Dairy Sci. 94:6047-6056. https://doi.org/10.3168/jds.2011 -4657 .

Haubold, S., C. Kröger-Koch, A. Starke, A. Tuchscherer, A. Tröscher, H. Kienberger, M. Rychlik, U. Bernabucci, E. Trevisi, and H. M. Hammon. 2020. Effects of abomasal infusion of essential fatty acids and conjugated linoleic acid on performance and fatty acid antioxidative, and inflammatory status in dairy cows. J. Dairy Sci. 103:972-991. https://doi.org/10.3168/jds.2019-17135.

Hötger, K., H. M. Hammon, C. Weber, S. Gors, A. Tröscher, R. M. Bruckmaier, and C. C. Metges. 2013. Supplementation of conjugated linoleic acid in dairy cows reduces endogenous glucose production during early lactation. J. Dairy Sci. 96:2258-2270. https:/ /doi.org/10.3168/jds.2012-6127.

Ishikawa, Y., K. Nakada, K. Hagiwara, R. Kirisawa, H. Iwai, M. Moriyoshi, and Y. Sawamukai. 2004. Changes in interleukin-6 concentration in peripheral blood of pre- and post-partum dairy cattle and its relationship to postpartum reproductive diseases. J. Vet. Med. Sci. 66:1403-1408. https://doi.org/10.1292/jvms.66.1403.

James, M. J., R. A. Gibson, and L. G. Cleland. 2000. Dietary polyunsaturated fatty acids and inflammatory mediator production. Am. J. Clin. Nutr. 71:343S-348S. https://doi.org/10.1093/ajcn/ 71.1.343s.

Jawor, P., A. Brzozowska, K. Sloniewski, Z. M. Kowalski, and T. Stefaniak. 2016. Acute phase response in the primiparous dairy cows after repeated percutaneous liver biopsy during the transition period. Pol. J. Vet. Sci. 19:393-399. https://doi.org/10.1515/pjvs -2016-0049.

Kamata, K., S. Manno, M. Ozaki, and Y. Takakuwa. 2008. Functional evidence for presence of lipid rafts in erythrocyte membranes: Gso in rafts is essential for signal transduction. Am. J. Hematol. 83:371-375. https://doi.org/10.1002/ajh.21126.

Kelly, M. L., E. S. Kolver, D. E. Bauman, M. E. Van Amburgh, and L. D. Muller. 1998. Effect of intake of pasture on concentrations of conjugated linoleic acid in milk of lactating cows. J. Dairy Sci. 
81:1630-1636. https://doi.org/10.3168/jds.S0022-0302(98)75730 -3 .

Lahlou, M. N., R. Kanneganti, L. J. Massingill, G. A. Broderick, Y. Park, M. W. Pariza, J. D. Ferguson, and Z. Wu. 2014. Grazing increases the concentration of CLA in dairy cow milk. Animal 8:1191-1200. https://doi.org/10.1017/S1751731114000998.

Lessard, M., N. Gagnon, and H. V. Petit. 2003. Immune response of postpartum dairy cows fed flaxseed. J. Dairy Sci. 86:2647-2657. https://doi.org/10.3168/jds.S0022-0302(03)73860-0.

Lokesh, B. R., T. J. Sayers, and J. E. Kinsella. 1990. Interleukin-1 and tumor-necrosis-factor synthesis by mouse peritoneal-macrophages is enhanced by dietary n-3 polyunsaturated fatty-acids. Immunol. Lett. 23:281-285. https://doi.org/10.1016/0165-2478(90)90073-Y.

Loor, J. J., H. M. Dann, R. E. Everts, R. Oliveira, C. A. Green, N. A Guretzky, S. L. Rodriguez-Zas, H. A. Lewin, and J. K. Drackley. 2005. Temporal gene expression profiling of liver from periparturient dairy cows reveals complex adaptive mechanisms in hepatic function. Physiol. Genomics 23:217-226. https://doi.org/10.1152/ physiolgenomics.00132.2005.

Loor, J. J., and J. H. Herbein. 2003. Dietary canola or soybean oil with two levels of conjugated linoleic acids (CLA) alter profiles of 18:1 and 18:2 isomers in blood plasma and milk fat from dairy cows. Anim. Feed Sci. Technol. 103:63-83. https://doi.org/10.1016/ S0377-8401(02)00259-6.

Malovrh, T., E. Melkic, D. Kompan, A. Levart, and L. Kompan. 2014. Incorporation of conjugated linoleic acid isomers into porcine erythrocytes. Eur. J. Nutr. 53:989-993. https://doi.org/10.1007/ s00394-013-0618-3.

Millar, H. R., J. G. Simpson, and A. L. Stalker. 1971. An evaluation of the heat precipitation method for plasma fibrinogen estimation. J. Clin. Pathol. 24:827-830. https://doi.org/10.1136/jcp.24.9.827.

Moallem, U. 2018. Invited review: Roles of dietary n-3 fatty acids in performance, milk fat composition, and reproductive and immune systems in dairy cattle. J. Dairy Sci. 101:8641-8661. https://doi .org/10.3168/jds.2018-14772.

Murata, H., and T. Miyamoto. 1993. Bovine haptoglobin as a possible immunomodulator in the sera of transported calves. Br. Vet. J. 149:277-283. https://doi.org/10.1016/S0007-1935(05)80173-3.

Nagao, K., and T. Yanagita. 2005. Conjugated fatty acids in food and their health benefits. J. Biosci. Bioeng. 100:152-157. https://doi .org/10.1263/jbb.100.152.

Nakagawa-Tosa, N., M. Morimatsu, M. Kawasaki, H. Nakatsuji, B. Syuto, and M. Saito. 1995. Stimulation of haptoglobin synthesis by interleukin- 6 and tumor-necrosis-factor, but not by interleukin-1, in bovine primary cultured-hepatocytes. J. Vet. Med. Sci. 57:219-223. https://doi.org/10.1292/jvms.57.219.

Naumann, C., and R. Bassler. 2012. Die chemische Untersuchung von Futtermitteln. VDLUFA-Verlag, Darmstadt, Germany.

Noble, R. C., J. H. Shand, and D. T. Calvert. 1982. The role of the placenta in the supply of essential fatty-acids to the fetal sheep: Studies of lipid compositions at term. Placenta 3:287-295. https:/ /doi.org/10.1016/S0143-4004(82)80005-2.

Palmquist, D. L. 2010. Essential fatty acids in ruminant diets. Pages 127-141 in Proc. 21st Annual Ruminant Nutrition Symposium, Gainesville, FL. Institute of Food and Agricultural Sciences, University of Florida, Gainesville, FL.

Pariza, M. W., Y. Park, and M. Cook. 2001. The biologically active isomers of conjugated linoleic acid. Prog. Lipid Res. 40:283-298. https://doi.org/10.1016/S0163-7827(01)00008-X.

Park, H. S., J. H. Ryu, Y. L. Ha, and J. H. Y. Park. 2001. Dietary conjugated linoleic acid (CLA) induces apoptosis of colonic mucosa in 1,2-dimethylhydrazine-treated rats: a possible mechanism of the anticarcinogenic effect by CLA. Br. J. Nutr. 86:549-555. https:// doi.org/10.1079/BJN2001445.

Petzold, M., U. Meyer, S. Kersten, J. Spilke, G. Breves, and S. Dänicke. 2015. Impacts of CLA and dietary concentrate proportion on blood metabolite concentration and proliferation of peripheral blood mononuclear cells of periparturient dairy cows. Animal 9:481-489. https://doi.org/10.1017/S175173111400264X.

Revskij, D., S. Haubold, T. Viergutz, C. Kröger-Koch, A. Tuchscherer, H. Kienberger, M. Rychlik, A. Tröscher, H. M. Hammon, H.-J.
Schuberth, and M. Mielenz. 2019. Dietary fatty acids affect red blood cell membrane composition and red blood cell ATP release in dairy cows. Int. J. Mol. Sci. 20:2769. https://doi.org/10.3390/ ijms20112769.

Ruijter, J. M., M. W. Pfaffl, S. Zhao, A. N. Spiess, G. Boggy, J. Blom, R. G. Rutledge, D. Sisti, A. Lievens, K. De Preter, S. Derveaux, J. Hellemans, and J. Vandesompele. 2013. Evaluation of qPCR curve analysis methods for reliable biomarker discovery: Bias, resolution, precision, and implications. Methods 59:32-46. https://doi.org/10 .1016/j.ymeth.2012.08.011.

Saremi, B., A. Al-Dawood, S. Winand, U. Müller, J. Pappritz, D. von Soosten, J. Rehage, S. Dänicke, S. Haussler, M. Mielenz, and H. Sauerwein. 2012a. Bovine haptoglobin as an adipokine: Serum concentrations and tissue expression in dairy cows receiving a conjugated linoleic acids supplement throughout lactation. Vet. Immunol. Immunopathol. 146:201-211. https://doi.org/10.1016/j .vetimm.2012.03.011.

Saremi, B., H. Sauerwein, S. Dänicke, and M. Mielenz. 2012b. Technical note: Identification of reference genes for gene expression studies in different bovine tissues focusing on different fat depots. J. Dairy Sci. 95:3131-3138. https://doi.org/10.3168/jds.2011-4803.

Schäfers, S., D. von Soosten, U. Meyer, C. Drong, J. Frahm, A Tröscher, W. Pelletier, H. Sauerwein, and S. Dänicke. 2018. Influence of conjugated linoleic acids and vitamin $\mathrm{E}$ on biochemical, hematological, and immunological variables of dairy cows during the transition period. J. Dairy Sci. 101:1585-1600. https://doi.org/10 .3168/jds.2017-13071.

Shingfield, K. J., L. Bernard, C. Leroux, and Y. Chilliard. 2010. Role of trans fatty acids in the nutritional regulation of mammary lipogenesis in ruminants. Animal 4:1140-1166. https://doi.org/10 $.1017 /$ S1751731110000510.

Shokryazdan, P., M. A. Rajion, G. Y. Meng, L. J. Boo, M. Ebrahimi, M. Royan, M. Sahebi, P. Azizi, R. Abiri, and M. F. Jahromi. 2017 Conjugated linoleic acid: A potent fatty acid linked to animal and human health. Crit. Rev. Food Sci. Nutr. 57:2737-2748. https:// doi.org/10.1080/10408398.2015.1060190.

Silvestre, F. T., T. S. Carvalho, P. C. Crawford, J. E. Santos, C. R. Staples, T. Jenkins, and W. W. Thatcher. 2011. Effects of differential supplementation of fatty acids during the peripartum and breeding periods of Holstein cows: II. Neutrophil fatty acids and function, and acute phase proteins. J. Dairy Sci. 94:2285-2301. https://doi.org/10.3168/jds.2010-3371.

Simopoulos, A. P. 2016. An increase in the omega-6/omega-3 fatty acid ratio increases the risk for obesity. Nutrients 8:128. https:// doi.org/10.3390/nu8030128.

Skinner, J. G., R. Brown, and L. Roberts. 1991. Bovine haptoglobin response in clinically defined field conditions. Vet. Rec. 128:147149. https://doi.org/10.1136/vr.128.7.147.

Sordillo, L. M. 2016. Nutritional strategies to optimize dairy cattle immunity. J. Dairy Sci. 99:4967-4982. https://doi.org/10.3168/jds .2015-10354.

Sordillo, L. M., G. M. Pighetti, and M. R. Davis. 1995. Enhanced production of bovine tumor necrosis factor-alpha during the periparturient period. Vet. Immunol. Immunopathol. 49:263-270. https:/ /doi.org/10.1016/0165-2427(95)05465-0.

Trevisi, E., M. Amadori, S. Cogrossi, E. Razzuoli, and G. Bertoni. 2012. Metabolic stress and inflammatory response in high-yielding, periparturient dairy cows. Res. Vet. Sci. 93:695-704. https://do .org/10.1016/j.rvsc.2011.11.008.

Trevisi, E., P. Grossi, F. P. Cappelli, S. Cogrossi, and G. Bertoni. 2011. Attenuation of inflammatory response phenomena in periparturient dairy cows by the administration of an $\omega 3$ rumen protected supplement containing vitamin E. Ital. J. Anim. Sci. 10:e61. https://doi.org/10.4081/ijas.2011.e61.

Trevisi, E., N. Jahan, G. Bertoni, A. Ferrari, and A. Minuti. 2015 Pro-inflammatory cytokine profile in dairy cows: Consequences for new lactation. Ital. J. Anim. Sci. 14:3862. https://doi.org/10 .4081/ijas.2015.3862.

Trevisi, E., F. Riva, J. F. S. Filipe, M. Massara, A. Minuti, P. Bani, and M. Amadori. 2018. Innate immune responses to metabolic 
stress can be detected in rumen fluids. Res. Vet. Sci. 117:65-73. https://doi.org/10.1016/j.rvsc.2017.11.008.

Viladomiu, M., R. Hontecillas, and J. Bassaganya-Riera. 2016. Modulation of inflammation and immunity by dietary conjugated linoleic acid. Eur. J. Pharmacol. 785:87-95. https://doi.org/10.1016/ j.ejphar.2015.03.095.

Vogel, L., M. Gnott, C. Kröger-Koch, D. Dannenberger, A. Tuchscherer, A. Tröscher, H. Kienberger, M. Rychlik, A. Starke, L. Bachmann, and H. M. Hammon. 2020. Effects of abomasal infusion of essential fatty acids together with conjugated linoleic acid in late and early lactation on performance, milk and body composition, and plasma metabolites in dairy cows. J. Dairy Sci. 103:7431-7450. https://doi.org/10.3168/jds.2019-18065.

Weber, C., C. Hametner, A. Tuchscherer, B. Losand, E. Kanitz, W. Otten, S. P. Singh, R. M. Bruckmaier, F. Becker, W. Kanitz, and H. M. Hammon. 2013. Variation in fat mobilization during early lactation differently affects feed intake, body condition, and lipid and glucose metabolism in high-yielding dairy cows. J. Dairy Sci. 96:165-180. https://doi.org/10.3168/jds.2012-5574.

Weber, C., A. Tröscher, H. Kienberger, M. Rychlik, and H. M. Hammon. 2016. Performance and fatty acid status in dairy cows fed a diet with reduced essential fatty acid content. Pages 245-246 in Energy and Protein Metabolism and Nutrition EAAP no. 137. J. Skomial and H. Lapierre, ed. Wageningen Academic, Wageningen, the Netherlands.

Zamaria, N. 2004. Alteration of polyunsaturated fatty acid status and metabolism in health and disease. Reprod. Nutr. Dev. 44:273-282 https://doi.org/10.1051/rnd:2004034.

\section{ORCIDS}

A. Tröscher @ https://orcid.org/0000-0002-4198-4427

E. Trevisi ৫ https://orcid.org/0000-0003-1644-1911

T. Stefaniak (1) https://orcid.org/0000-0002-8982-211X

J. Bajzert @ https://orcid.org/0000-0002-1299-7405

M. Mielenz @ https://orcid.org/0000-0002-5465-5817

L. Bachmann @ https://orcid.org/0000-0003-0681-4999

H. M. Hammon @ ( https://orcid.org/0000-0001-8698-1257 